\title{
Pharmacokinetics and Target Attainment of Antibiotics in Critically III Children: A Systematic Review of Current Literature
}

\author{
Stan J. F. Hartman ${ }^{1}$ (D) Roger J. Brüggemann ${ }^{2} \cdot$ Lynn Orriëns $^{1} \cdot$ Nada Dia $^{1} \cdot$ Michiel F. Schreuder $^{3}$. \\ Saskia N. de Wildt ${ }^{1,4,5}$
}

Published online: 20 August 2019

(c) The Author(s) 2019

\begin{abstract}
Background Pharmacokinetics (PK) are severely altered in critically ill patients due to changes in volume of distribution $(\mathrm{Vd})$ and/or drug clearance $(\mathrm{Cl})$. This affects the target attainment of antibiotics in critically ill children. We aimed to identify gaps in current knowledge and to compare published PK parameters and target attainment of antibiotics in critically ill children to healthy children and critically ill adults.

Methods Systematic literature search in PubMed, EMBASE and Web of Science. Articles were labelled as relevant when they included information on PK of antibiotics in critically ill, non-neonatal, pediatric patients. Extracted PK-parameters included $\mathrm{Vd}, \mathrm{Cl}$, (trough) concentrations, AUC, probability of target attainment, and elimination half-life.

Results 50 relevant articles were identified. Studies focusing on vancomycin were most prevalent (17/50). Other studies included data on penicillins, cephalosporins, carbapenems and aminoglycosides, but data on ceftriaxone, ceftazidime, penicillin and metronidazole could not be found. Critically ill children generally show a higher $\mathrm{Cl}$ and larger Vd than healthy children and critically ill adults. Reduced target-attainment was described in critically ill children for multiple antibiotics, including amoxicillin, piperacillin, cefotaxime, vancomycin, gentamicin, teicoplanin, amikacin and daptomycin. 38/50 articles included information on both $\mathrm{Vd}$ and $\mathrm{Cl}$, but a dosing advice was given in only 22 articles.

Conclusion The majority of studies focus on agents where TDM is applied, while other antibiotics lack data altogether. The larger $\mathrm{Vd}$ and higher $\mathrm{Cl}$ in critically ill children might warrant a higher dose or extended infusions of antibiotics in this patient population to increase target-attainment. Studies frequently fail to provide a dosing advice for this patient population, even if the necessary information is available. Our study shows gaps in current knowledge and encourages future researchers to provide dosing advice for special populations whenever possible.
\end{abstract}

Electronic supplementary material The online version of this article (https://doi.org/10.1007/s40262-019-00813-w) contains supplementary material, which is available to authorized users.

Stan J. F. Hartman

stan.hartman@radboudumc.nl

1 Department of Pharmacology-Toxicology, Radboudumc, Geert Grooteplein Zuid 10, 6525 GA Nijmegen, The Netherlands

2 Department of Pharmacy, Radboudumc, Nijmegen, The Netherlands

3 Division of Pediatric Nephrology, Department of Pediatrics, Radboudumc Amalia Children's Hospital, Nijmegen, The Netherlands

4 Department of Intensive Care Medicine, Radboudumc, Nijmegen, The Netherlands

5 Intensive Care and Department of Pediatric Surgery, Erasmus MC-Sophia Children's Hospital, University Medical Center Rotterdam, Rotterdam, The Netherlands

\section{Key Points}

This review provides a complete and comprehensive overview of all studies regarding pharmacokinetics and target attainment of all antibiotic agents in critically ill children.

Current knowledge gaps include several frequently used antibiotics, such as ceftriaxone, ceftazidime, penicillin, flucloxacillin and metronidazole that lack data altogether in this patient population.

This literature overview hopes to inspire researchers to close these gaps, not only by publishing pharmacokinetic data, but also by providing dosing guidance for implementation in the clinic, as this information is vital to optimize antibiotic treatment in this vulnerable population. 


\section{Introduction}

Antibiotics make up the most common class of drugs prescribed to hospitalized children, with roughly $50 \%$ of patients receiving an antibiotic agent during their hospital stay [1]. In critically ill children, the prophylactic and therapeutic use of intravenous antibiotics is even more prevalent [1].

Currently, critically ill children are generally started on the same (weight-corrected) dose of antibiotic therapy as their non-critically ill counterparts. As a consequence of altered pharmacokinetics (PK) due to critical illness there is a high likelihood that target concentrations, associated with optimal efficacy while minimizing toxicity, are not attained. In intensive care unit (ICU) patients, antibiotic concentrations are outside of the therapeutic window in up to $41 \%$ of adult patients [2] and even $95 \%$ in a critically ill pediatric ICU (PICU) population [3]. This non-target attainment in critically ill patients is caused by pathophysiological changes in volume of distribution (Vd), protein binding and/ or drug clearance $(\mathrm{Cl})$ [4-6]. Contrary to renal dysfunction, an increased renal clearance caused by hemodynamic alterations during critical illness, described as augmented renal clearance (ARC), is reported in up to $65 \%$ of critically ill adults [7, 8] and children [9, 10].

In addition to these pathophysiological alterations, young children also show developmental changes in almost all processes involved in drug disposition. Apart from differences in body composition, children also show maturation of drug metabolizing enzymes and glomerular filtration rate (GFR) in the first years of life [11]. Currently, most pediatric dosing guidelines for children older than 1 month (e.g. British National Formulary for Children and Dutch Pediatric Formulary) only present a single body-weight based dose, not accounting for these developmental changes.

Whether these changes in drug disposition lead to nontarget attainment of antibiotics in patients obviously also depends on the pharmacodynamic (PD) interaction between antibiotic and micro-organism. The two main parameters in this interaction are the susceptibility of the micro-organism, defined as the minimum inhibitory concentration (MIC), and the kill-characteristic of the antibiotic [4]. Different classes of antibiotics have different kill-characteristics and can be divided in time-dependent, concentration dependent and exposure dependent antibiotics [4]. When the killcharacteristic of an antibiotic are known, PD targets can be established for these antibiotics. Common PD targets for time-dependent, concentration dependent and exposure dependent antibiotics are the time free drug concentrations are above the MIC at the site of infection (fT $>$ MIC), peak concentration over MIC (Cmax/MIC) and area under the curve (AUC) over MIC (AUC/MIC), respectively. Subsequently, the probability of reaching these targets in special populations, such as critically ill children, can be simulated using PK data [12].

Knowledge of altered PK parameters and desired PD targets is essential to serve as the basis for the development of individualized starting dosing guidelines and further individualized dose adjustments using therapeutic drug monitoring (TDM). Multiple studies have shown that the application of TDM improves target attainment of antibiotic agents in critically ill patients [3, 13-16].

The aim of this systematic review is to summarize the reported PK data and target attainment of antibiotics in critically ill children, in relation data from non-critically ill children and/or critically ill adult patients. This may aid to identify gaps in current knowledge for future research, to optimize dosing guidelines and support TDM practice.

\section{Methods}

\subsection{Search Strategy}

We performed a systematic search in concordance with PRISMA guidelines in MEDLINE (using PubMed), EMBASE and Web of Science databases from 1900 to April 2017. The PRISMA checklist is included as Supplemental Data File 1. Researchers were alerted to additional results for the search after April 2017 until May 15th 2019 by automatic e-mail alerts, and articles after this period were screened and selected in the same manner as articles in the original search. Duplicate articles within each database and between databases were excluded by using EndNote and manual selection. The main research question was broken down into four domains (Pharmacokinetics, Antibiotics, Critically ill and Children). Keywords were allocated to these domains and as many synonyms for each keyword as possible were included in the search. Whenever possible, keywords were converted to corresponding MeSH-terms and/or subject headings. In the final search, both MeSH-terms, Subject Headings and keywords in the title and abstract were included. In order to include all antibiotic agents for the 'Antibiotic' domain in our search, we used the term "Anti-Bacterial Agents" [Pharmacological Action] from the MeSH Database in combination with a free text search built with all the drug names and substance names linked to this MeSH-term [17]. Antiviral and antifungal therapies were left out of the scope of this systematic review. An overview of the final search strategy is depicted in Table 1 and a full list of antibiotic agents in Supplemental Data File 2.

\subsection{Study Selection}

The title and abstract of every result in the search were screened for eligibility by SH, ND and LO. A study was 
labelled as eligible when it contained information on all four domains (Pharmacokinetics, Antibiotics, Critically ill and Children). Studies were labelled as ineligible when information on one or more domains was missing, when the study population consisted of only adults or neonates ( $<1$ month old), and/or when all patients were treated with renal replacement therapy or extracorporeal membrane oxygenation because of the direct influence on $\mathrm{Vd}$ and $\mathrm{Cl}$ depending on the extracorporeal circuit. Critical illness was based solely on the mention of ICU admission, regardless of disease severity scores, organ dysfunction or diagnoses of patients. This was done in order to best reflect the heterogenous PICU population and identify the impact of (critical) illness on their PK parameters. When the study population consisted of a mix of critically ill children and non-critically ill children, neonates or adults studies were only included when PK data of the critically ill children was reported separately. Other exclusion criteria were non-English articles, conference abstracts, letters to the editor, no full-text availability, animal studies, in vitro studies and/or oral dosing. Review articles were also excluded but the references in these reviews were screened for additional relevant articles not identified by our search.

Overlapping articles were included and non-overlapping articles between the three reviewers were screened again by $\mathrm{SH}$ and $\mathrm{SdW}$ and included if labelled as eligible by both researchers.

\subsection{Data Extraction}

For each eligible article data was systematically extracted and all the extracted data was entered in a database using Microsoft Excel. The extracted data included type of antibiotic studied, study design, dose, sample size, type of population, disease severity based on validated clinical scores (PELOD, PIM, PRISM-scores or STAT categories), renal dysfunction and age of subjects. In addition, the PKanalysis used in the article was studied, whether a (Pop)PK model was used, how many compartments were included in the model, studied co-variates on PK, what PK-parameters were found, and any additional findings of interest were noted. Lastly, when a dosing advice for critically ill children was provided, this was noted.

The PK-parameters of interest that were collected were $\mathrm{Vd}, \mathrm{Cl}$, trough $(\mathrm{Cmin})$ and peak $(\mathrm{Cmax})$ concentrations, AUC, half-life $\left(t^{1 / 2}\right)$ and elimination rate constant $(k)$. All values of PK-parameters were normalized in order to ease comparability between different studies. $\mathrm{Vd}$ was normalized to liters/kilogram $(1 / \mathrm{kg})$ and $\mathrm{Cl}$ values to $1 / \mathrm{kg} / \mathrm{h}(1 / \mathrm{kg} / \mathrm{h})$. In case of allometric scaling or covariate contribution to one of these parameters, which is often seen in pharmacometric models, the covariate values of a mean/median study patient were used to normalize PK-parameter values.

PD parameters that were collected included the probability of target attainment (PTA), MIC and PD targets for time-dependent, concentration dependent and exposure dependent antibiotics: fT > MIC, AUC/MIC and Cmax/MIC, respectively.

\section{Results}

The literature search in PubMed, EMBASE and Web of Science yielded 1742 articles. After the exclusion of duplicate articles within each database and between the 3 databases a total of 1313 articles were screened. From the screening process a total of 70 articles were labelled as eligible (Fig. 1).

Table 1 Overview of final search strategy in PubMed with MeSH (Medical Subject Headings) terms and free text keywords for each of the four domains (Pharmacokinetics, Antibiotics, Critically ill, and Children)

\begin{tabular}{|c|c|c|c|}
\hline Pharmacokinetics & Antibiotics & Critically ill & Children \\
\hline $\begin{array}{l}\text { MeSH terms } \\
\text { Pharmacokinetics [Mesh] } \\
\text { Pharmacokinetics [Subheading] } \\
\text { Monte Carlo Method [Mesh] } \\
\text { Drug Monitoring [Mesh] } \\
\text { Drug Dosage Calculations [Mesh] }\end{array}$ & $\begin{array}{l}\text { MeSH-terms } \\
\text { Anti-Bacterial } \\
\text { Agents [Phar- } \\
\text { macological } \\
\text { Action] } \\
\text { Anti-Bacterial } \\
\text { Agents [Mesh] }\end{array}$ & $\begin{array}{l}\text { MeSH terms } \\
\text { Intensive Care Units [Mesh] } \\
\text { Critical Illness [Mesh] } \\
\text { Critical Care [Mesh] }\end{array}$ & $\begin{array}{l}\text { MeSH terms } \\
\text { Adolescent [Mesh] } \\
\text { Child [Mesh] } \\
\text { Infant [Mesh] }\end{array}$ \\
\hline $\begin{array}{l}\text { Title/abstract } \\
\text { Peak concentration*, Trough concentra- } \\
\text { tion*, Area Under Curve, Therapeutic } \\
\text { Equivalency, Tissue Distribution, } \\
\text { Pharmacokinetic*, PopPK, Target- } \\
\text { attainment, Drug monitoring, TDM, } \\
\text { Pharmacodynamic*, Dose calculation*, } \\
\text { Drug dos* }\end{array}$ & $\begin{array}{l}\text { Title/abstract } \\
\text { See Electronic } \\
\text { Supplementary } \\
\text { Material }\end{array}$ & $\begin{array}{l}\text { Title/abstract } \\
\text { Severe ill, severe illn*, severely ill, PICU, } \\
\text { PICUs, ICU, ICUs, Critical Care, Inten- } \\
\text { sive Care Unit*, serious illn*, serious } \\
\text { ill, seriously ill, critical illn*, critical ill, } \\
\text { critically ill* }\end{array}$ & $\begin{array}{l}\text { Title/abstract } \\
\text { Child*, schoolchild*, infan*, } \\
\text { adolescen*, pediatri*, paediatr*, } \\
\text { boy, boys, boyhood, girl, girls, girl- } \\
\text { hood, youth, youths, baby, babies, } \\
\text { toddler*, teen, teens, teenager*, } \\
\text { postnat*, puberty, preschool*, } \\
\text { suckling*, picu }\end{array}$ \\
\hline
\end{tabular}

Terms within each domain were combined with OR, all domains were combined with AND, as shown in the Electronic Supplementary Material 
Twenty-three of the included articles did contain information on the PK of antibiotic agents in a population of critically ill children but results were mixed with either adult data or non-critically ill data and therefore excluded. One article [18] was included from the references of included articles and/or reviews regarding the subject. Additionally, two articles that did not come up during the systematic review and were not mention in references of reviews were added after the peer-review process [19, 20]. Data-extraction was performed for 50 full-text articles with data on the PK of antibiotics in critically ill children. A complete list of all 50 articles and extracted PK-data is presented in Table 2.

\section{1 $\beta$-Lactam Antibiotics}

\subsubsection{Penicillins}

3.1.1.1 Amoxicillin and Clavulanic Acid Both studies on amoxicillin PK included patients that were treated with amoxicillin combined with clavulanic acid as a $\beta$-lactamase inhibitor [21, 22]. Doses used in the studies ranged from a single dose of $50 \mathrm{mg} / \mathrm{kg}$ amoxicillin and $5 \mathrm{mg} / \mathrm{kg}$ clavulanic acid to $100 \mathrm{mg} / \mathrm{kg} /$ day of amoxicillin and $20 \mathrm{mg} / \mathrm{kg}$ clavulanic acid every $6 \mathrm{~h}$. Patient characteristics within these 2 studies varied: Jones et al. [22] studied 15 children with pneumonia, asthma or pyelonephritis who were slightly older than the 50 patients in the study by de Cock [21]. In addition, data on renal function were not reported by Jones, nor was there any information on disease severity. The study by De Cock et al. included a varied PICU population of which $44 \%$ received the combination for postoperative prophylaxis. Patients had a median (range) PRISM-score of 6.5 (0-32) and median (range) PELOD score of 1 (0-31).

Median estimated Vd was 0.368 and $0.4691 / \mathrm{kg}$ for amoxicillin and 0.306 and $0.434 \mathrm{l} / \mathrm{kg}$ for clavulanic acid for the De Cock and Jones study, respectively. $\mathrm{Cl}$ of amoxicillin, normalized to $1 / \mathrm{kg} / \mathrm{h}$, was comparable between both studies at 0.242 and $0.257 \mathrm{l} / \mathrm{kg} / \mathrm{h}$, whereas clavulanic acid $\mathrm{Cl}$ was slightly higher in the study by Jones et al. $(0.256 \mathrm{l} / \mathrm{kg} / \mathrm{h})$ compared to $0.174 \mathrm{l} / \mathrm{kg} / \mathrm{h}$ in the study by De Cock et al.

De Cock et al. estimated PK-parameters using population PK (PopPK) modelling. They identified weight, postmenstrual age, cystatin $\mathrm{C}$ based estimated GFR (eGFR) and vasopressor treatment as significant co-variates on either $\mathrm{Vd}$ and/or $\mathrm{Cl}$ of amoxicillin and clavulanic acid. Target attainment, which was defined as $\mathrm{fT}>\mathrm{MIC}$ of $40 \%$ against an MIC of $8 \mathrm{mg} / \mathrm{l}$, was reported only for clavulanic acid for 3 different dosing regimens, including dosing regimens of $25 \mathrm{mg} /$ $\mathrm{kg}$ every 4-12 $\mathrm{h}$ the authors based on the British National Formulary for Children and Samford Guide for Antibiotic Therapy. Target attainment was estimated at 48-96\% for bolus infusions and 53-99\% for extended infusions of $1 \mathrm{~h}$. Target attainment for amoxicillin was not reported in exact numbers but was identified from figures. Target attainment of time above MIC of $8 \mathrm{mg} / \mathrm{l}$ ranged from 10 to $85 \%$ for three different dosing schemes using bolus injections in children with no vasopressors and no renal dysfunction.
Fig. 1 A total of 1742 articles were screened from the 3 databases. After excluding duplicates and non-eligible articles and including articles from references a total of 48 eligible articles were analyzed for data extraction. $R R T$ renal replacement therapy, ECMO extracorporeal membrane oxygenation, $I C U$ intensive care unit

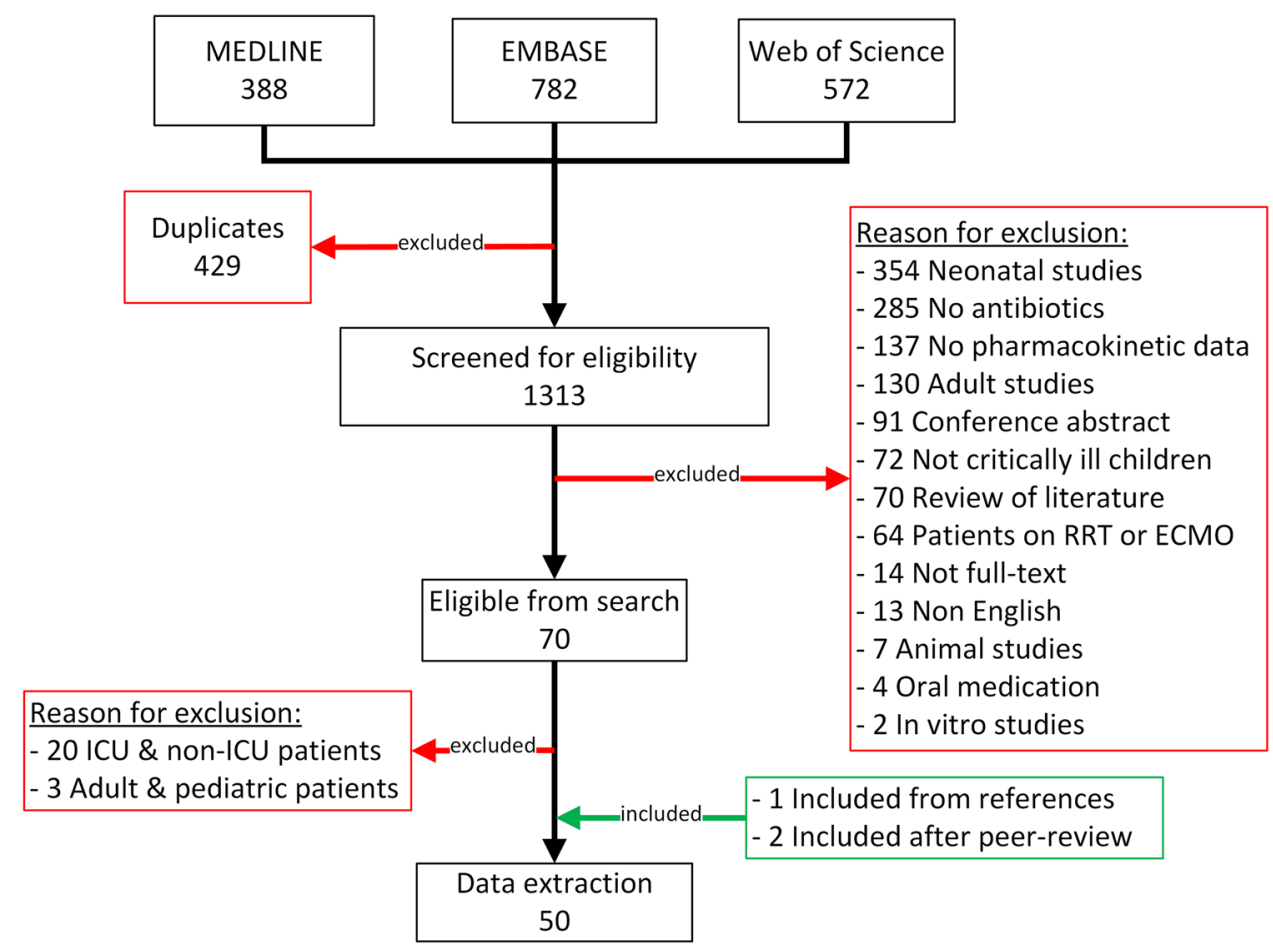




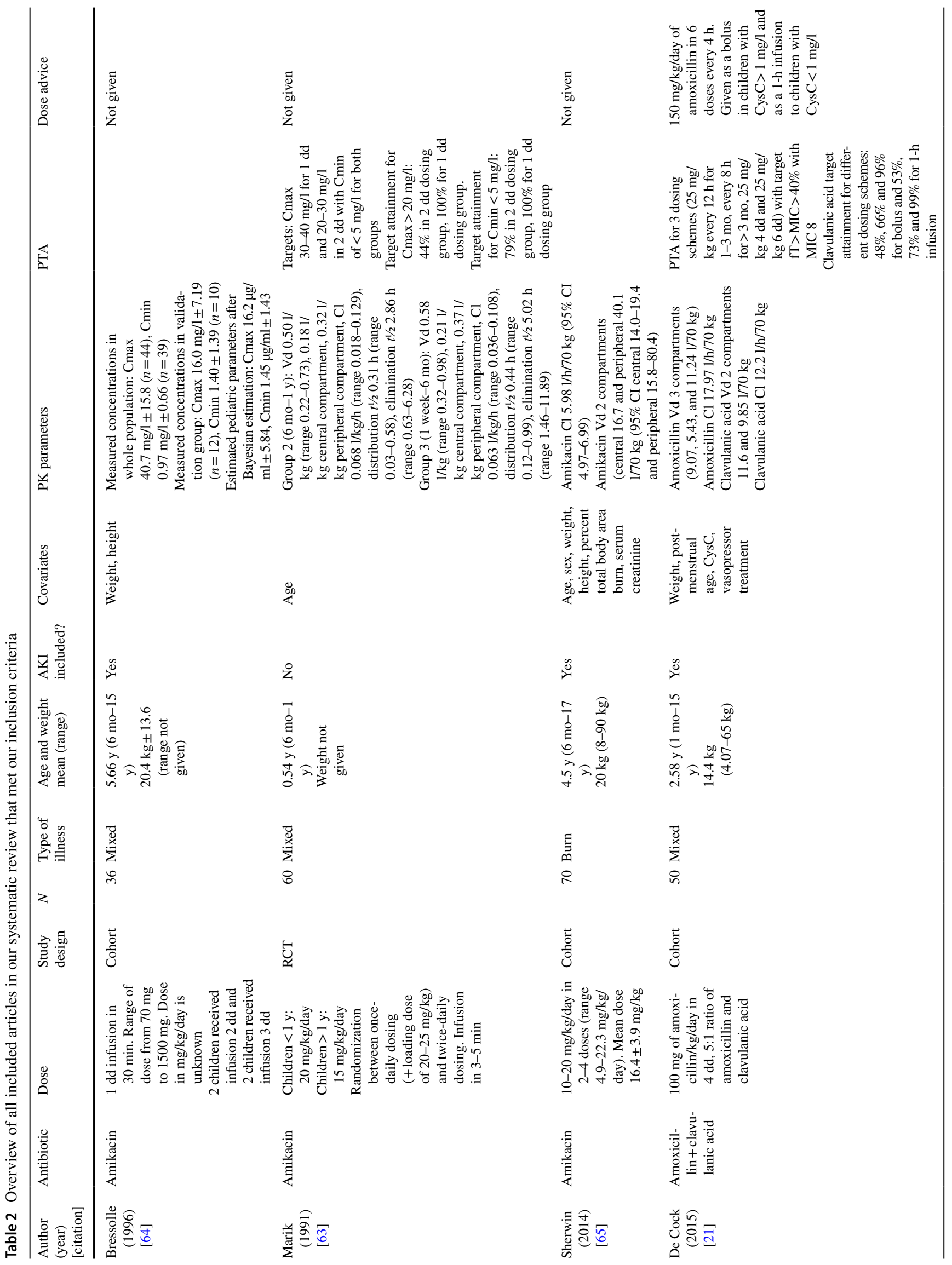




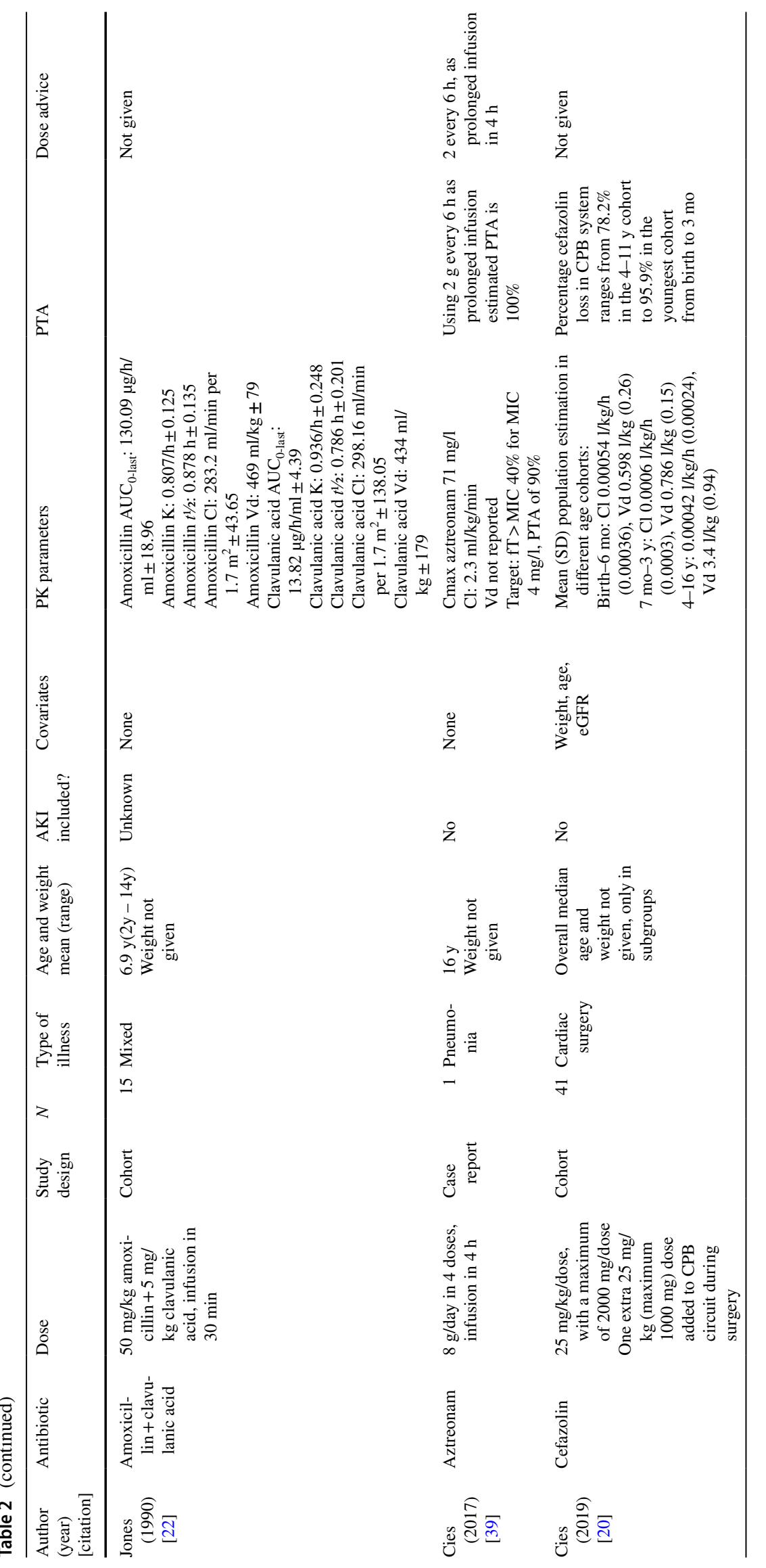




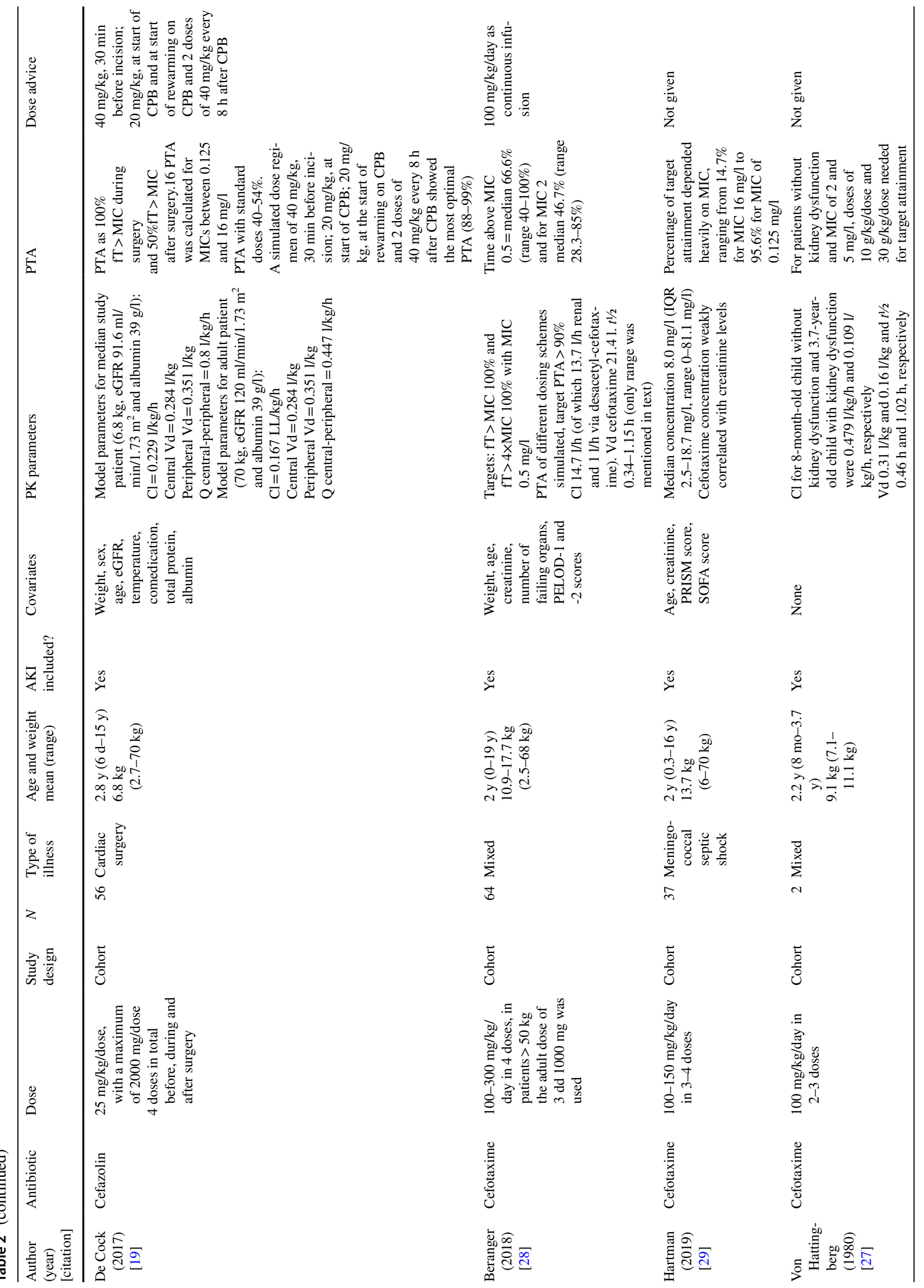




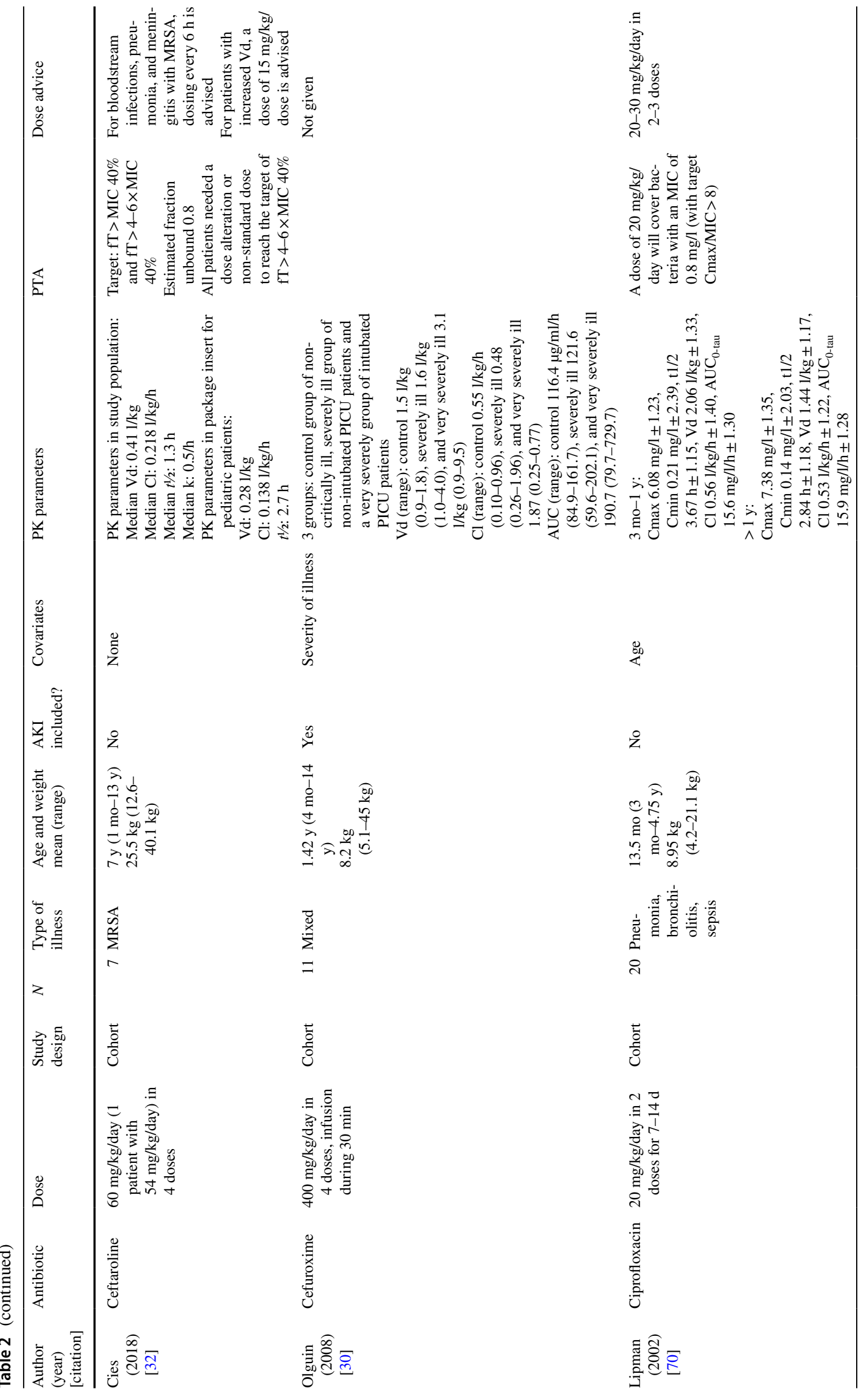




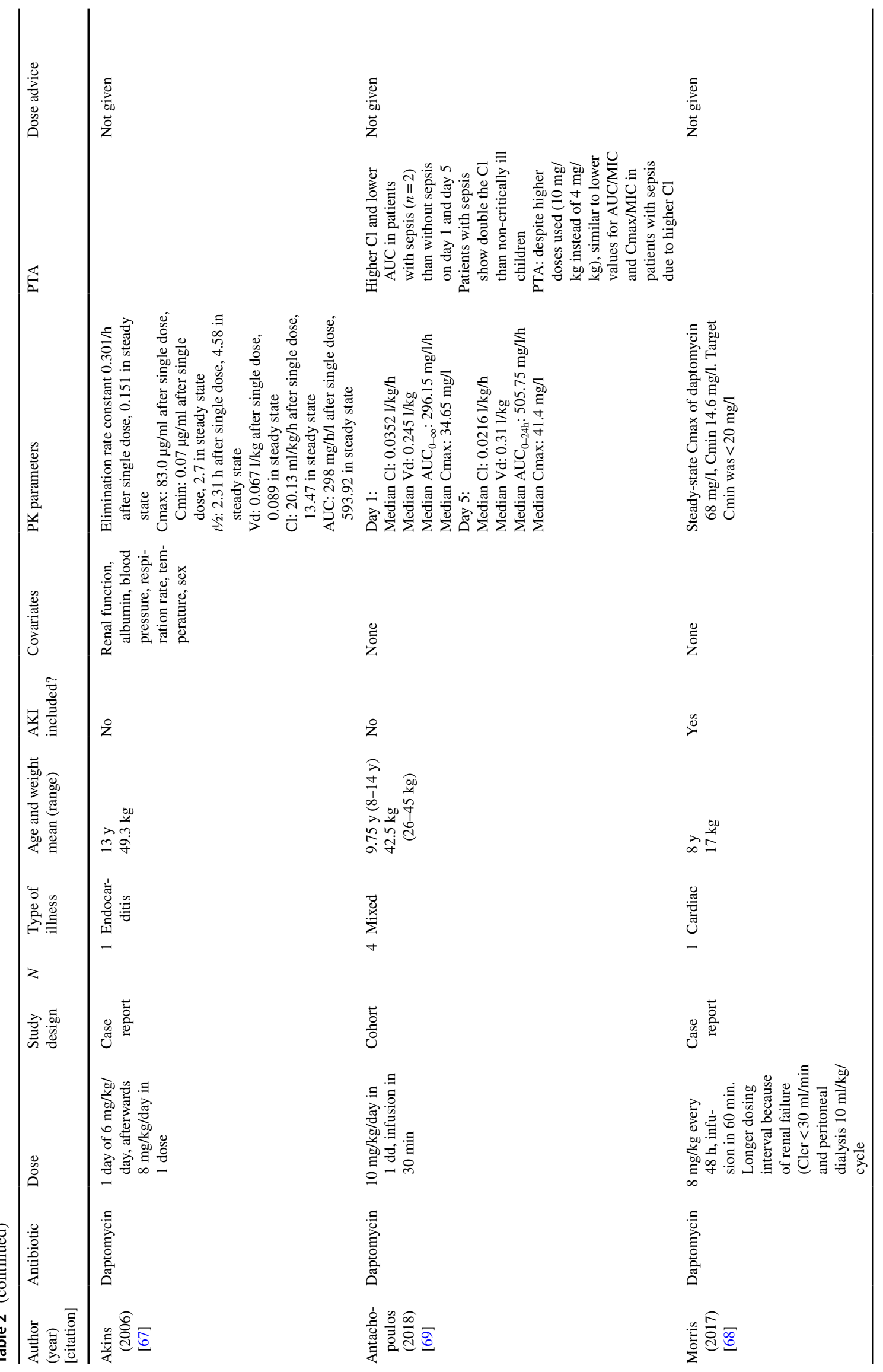




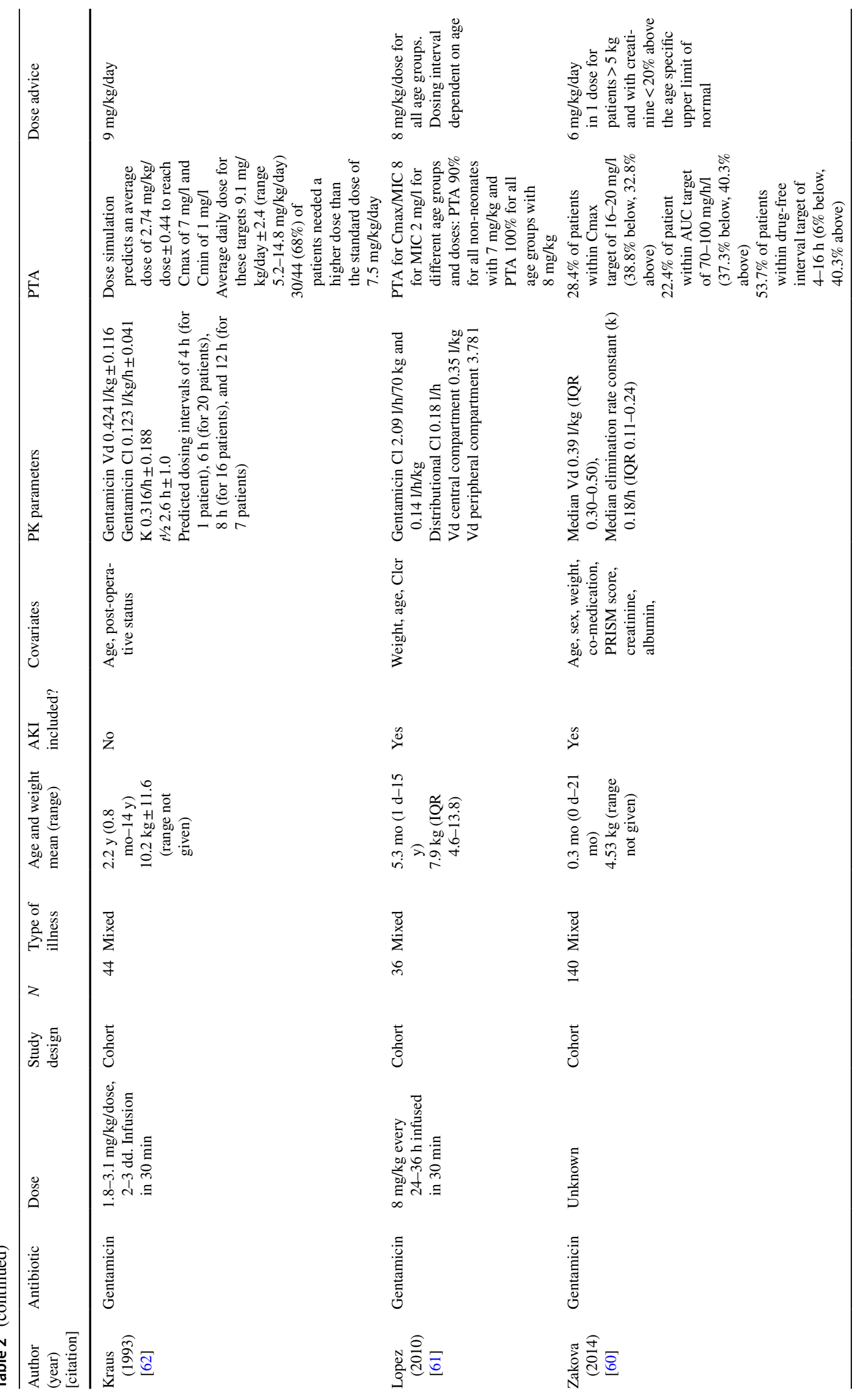




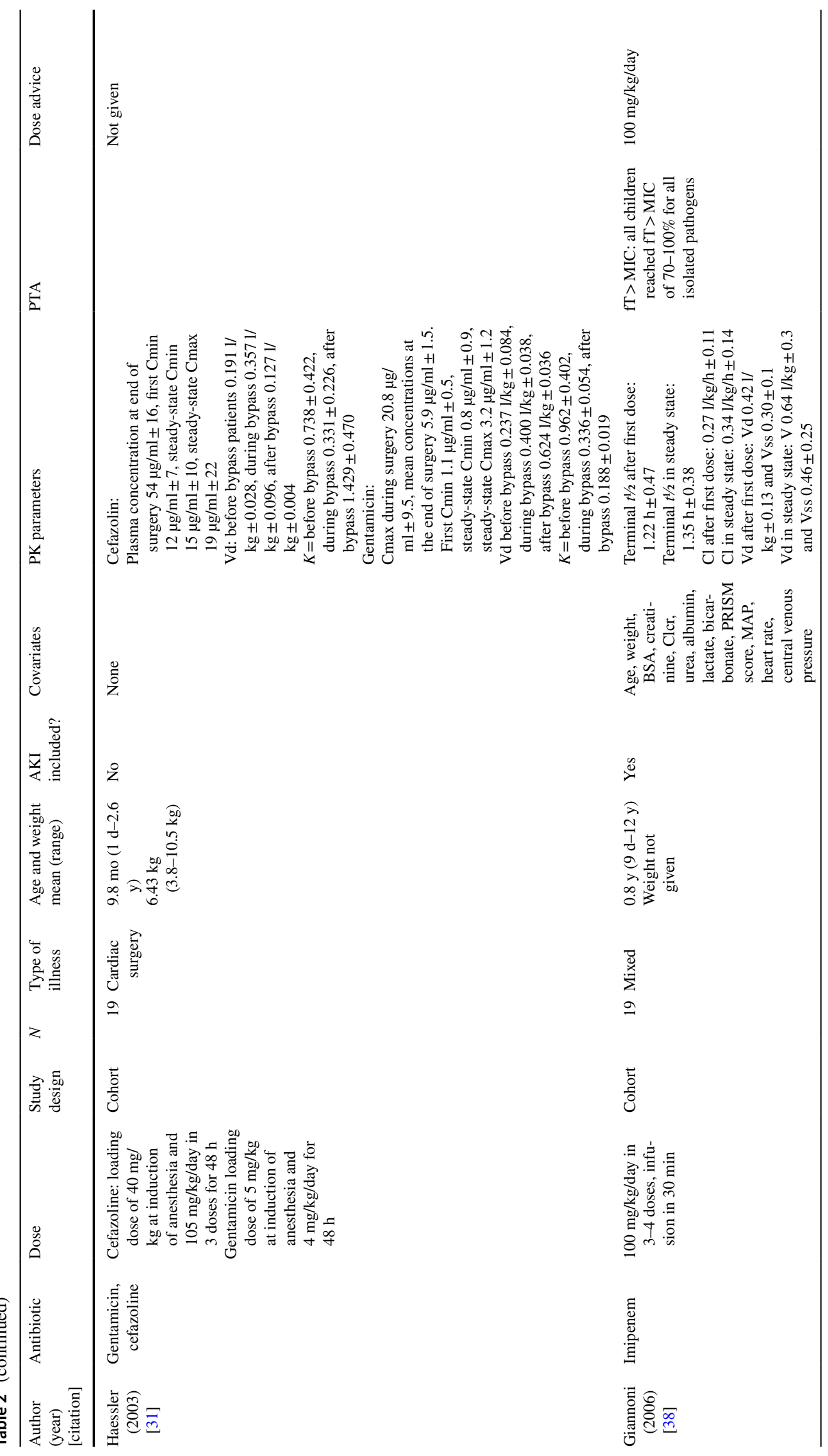




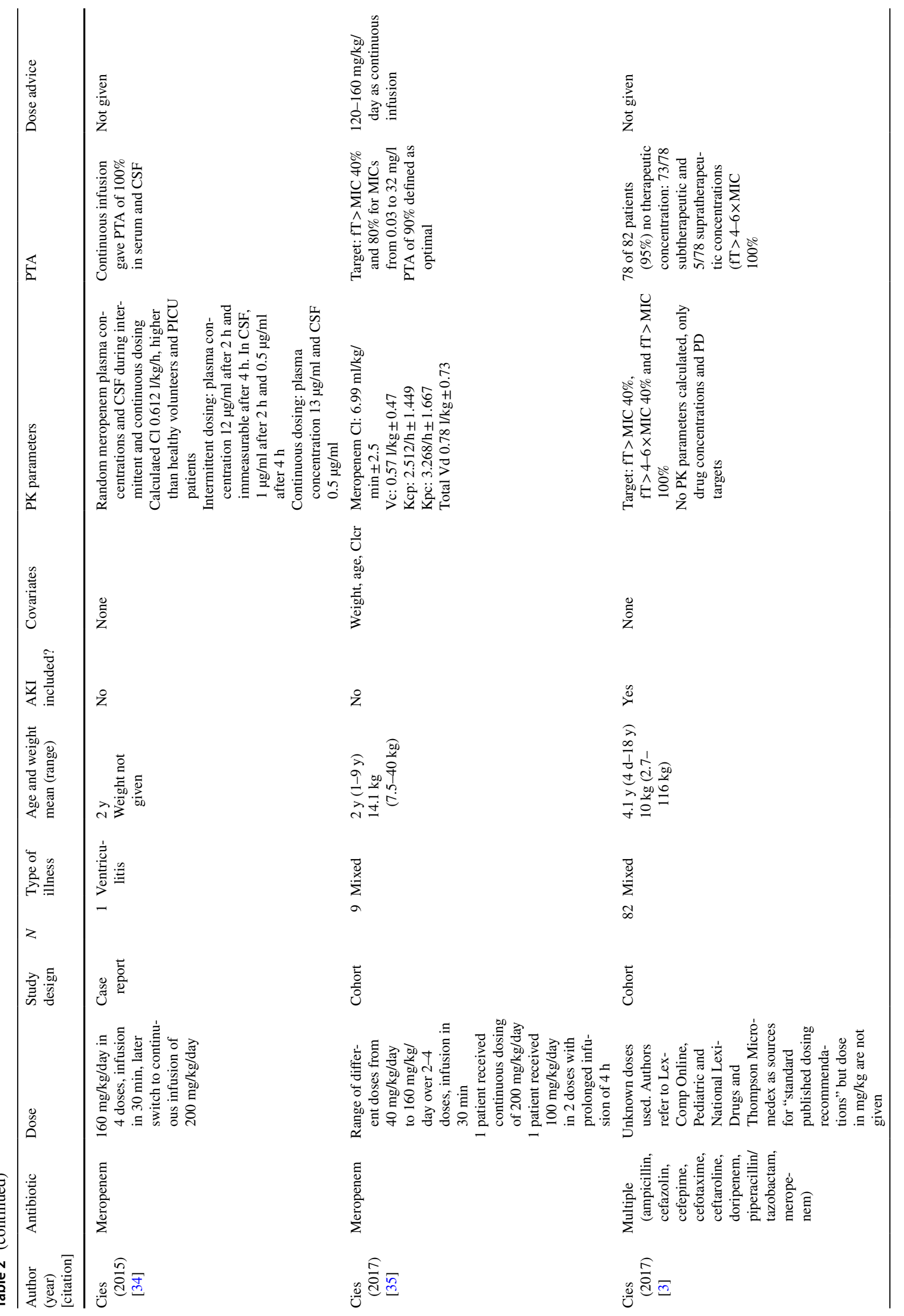









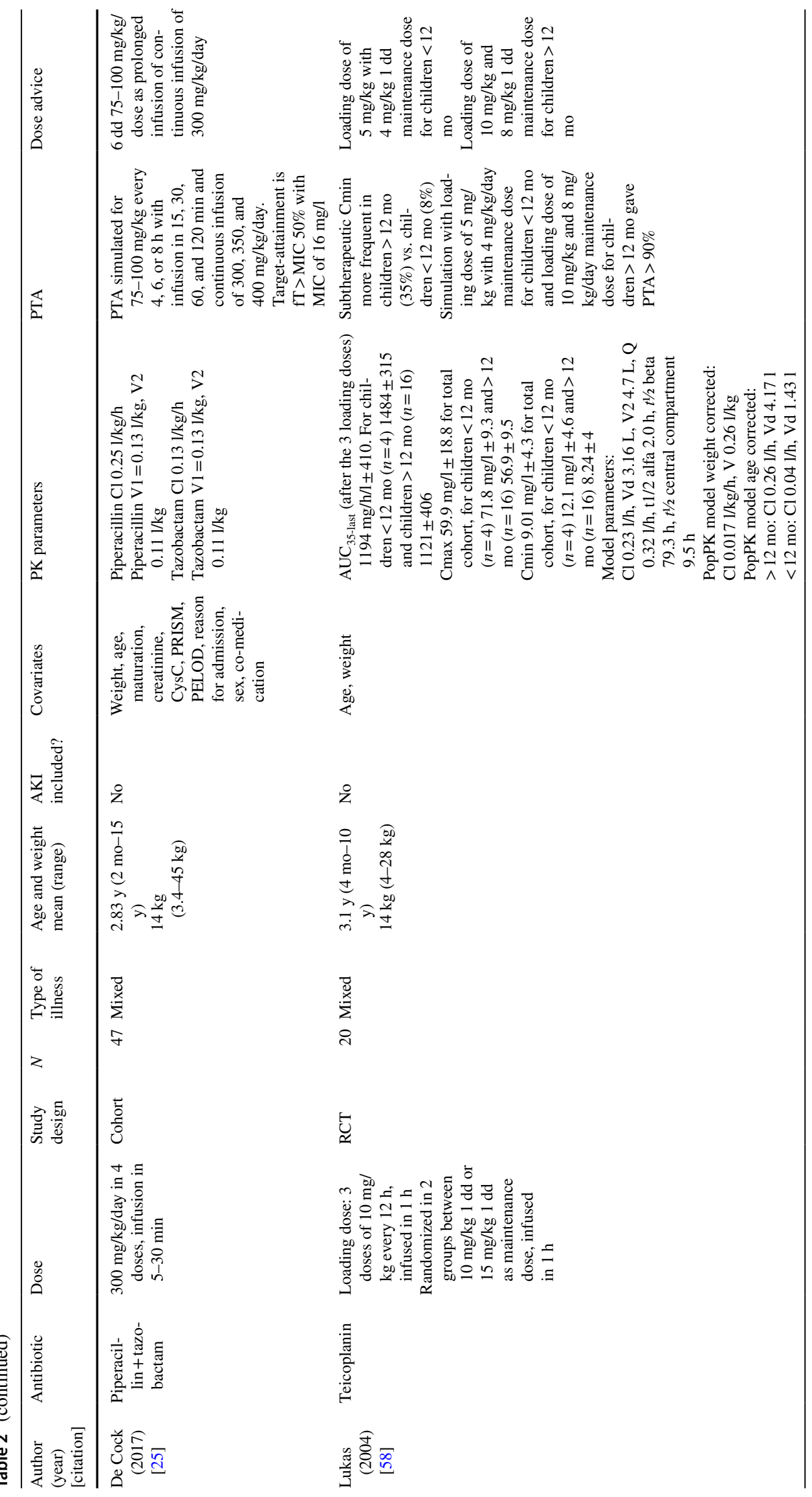




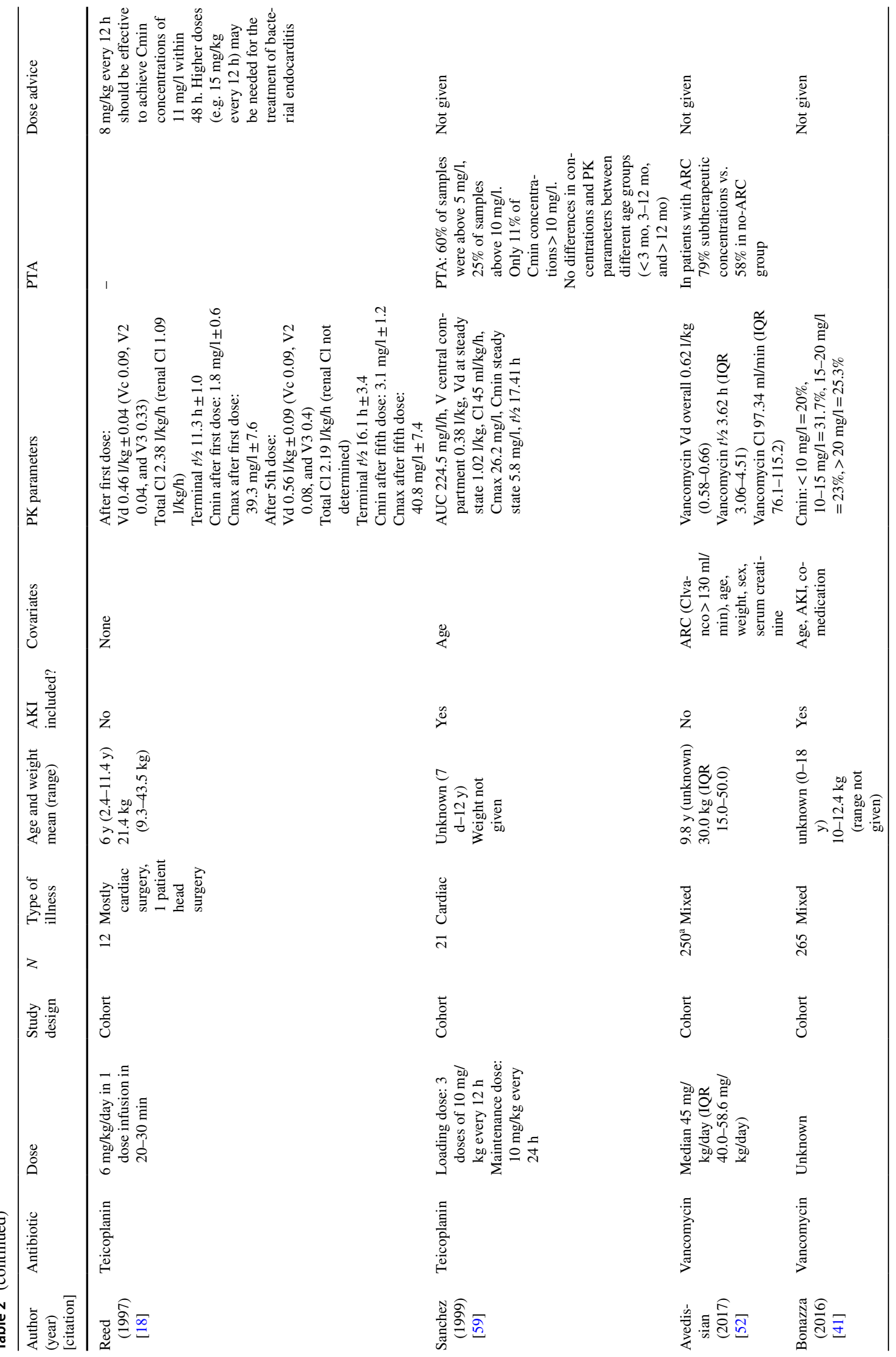




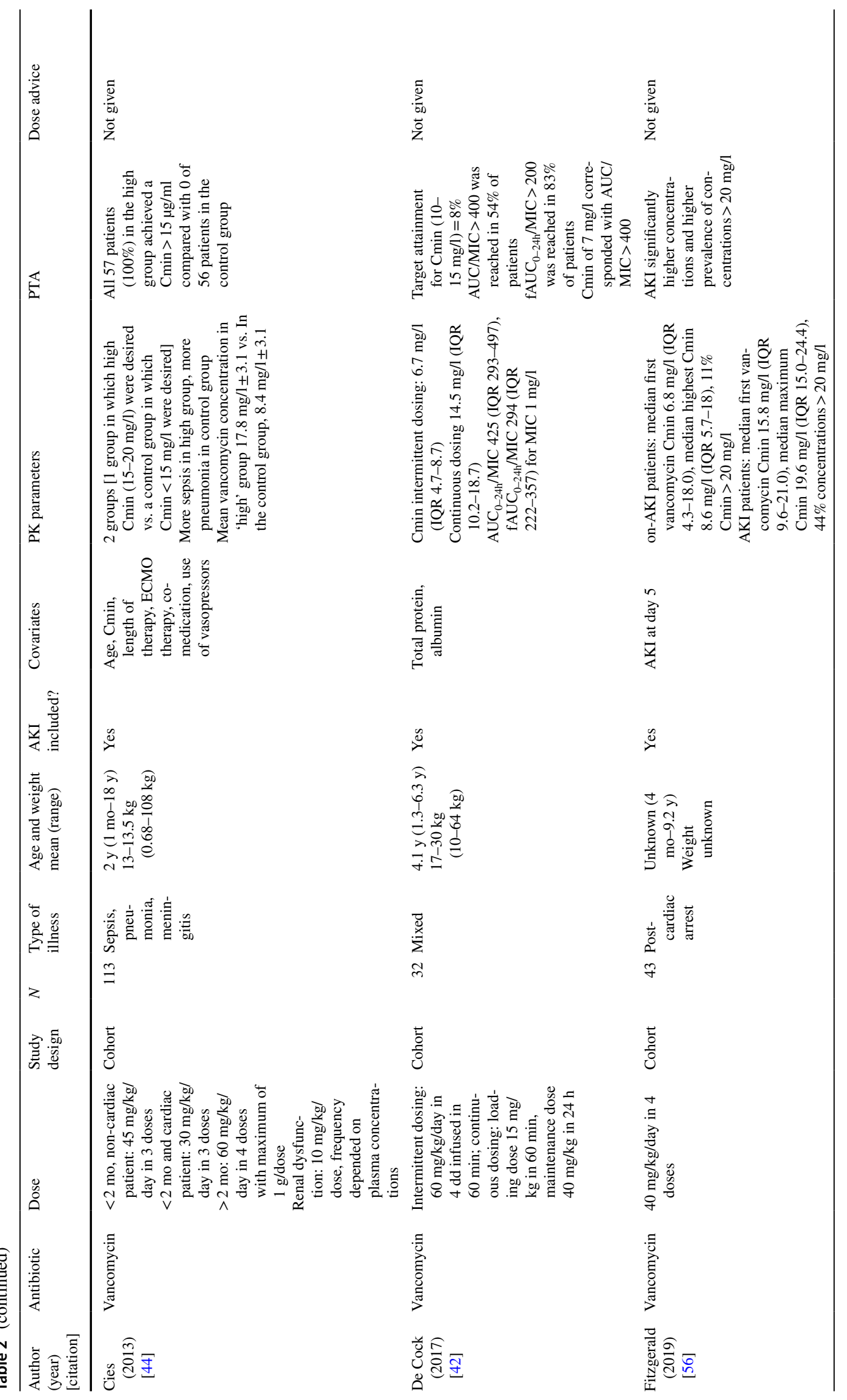




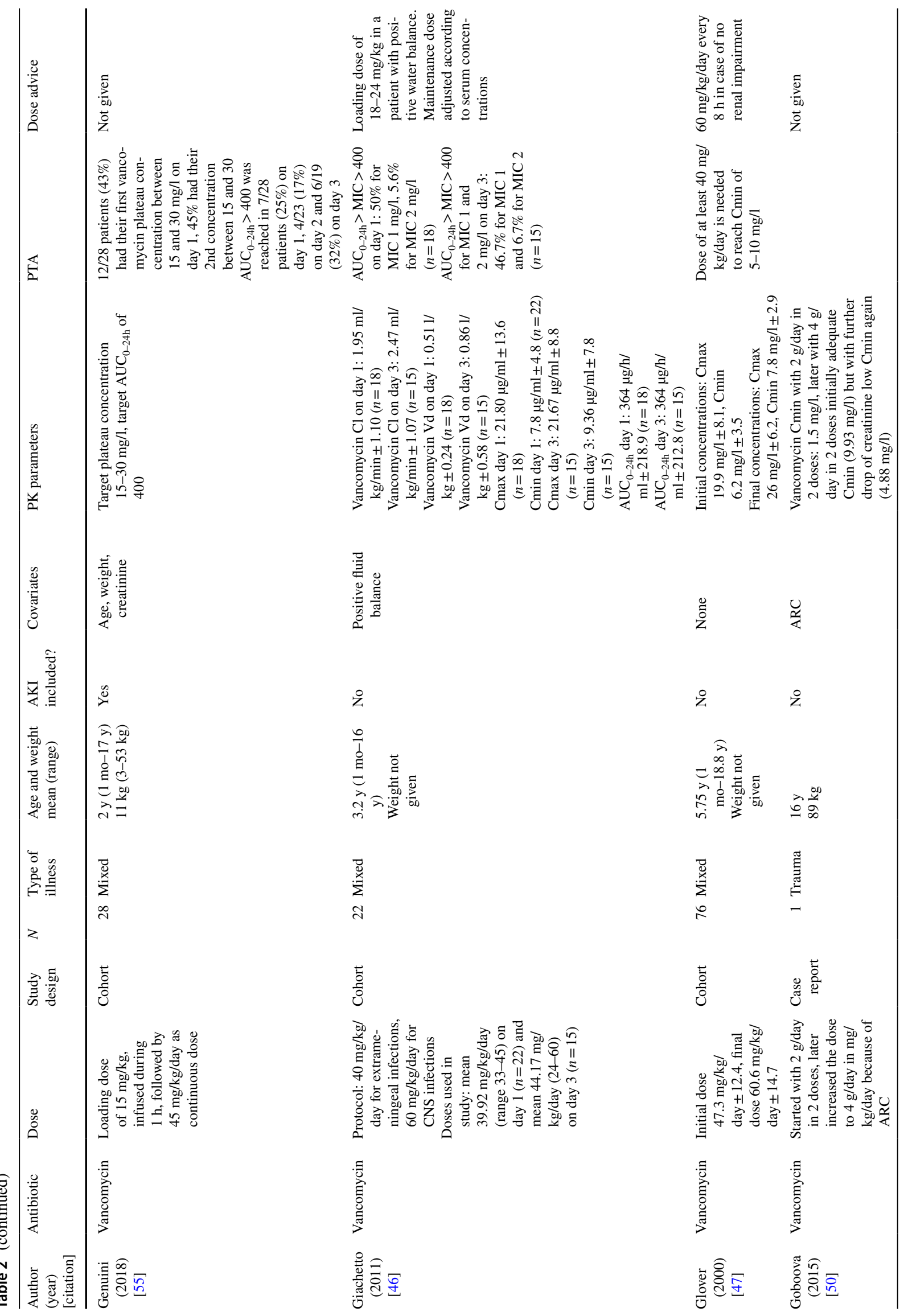




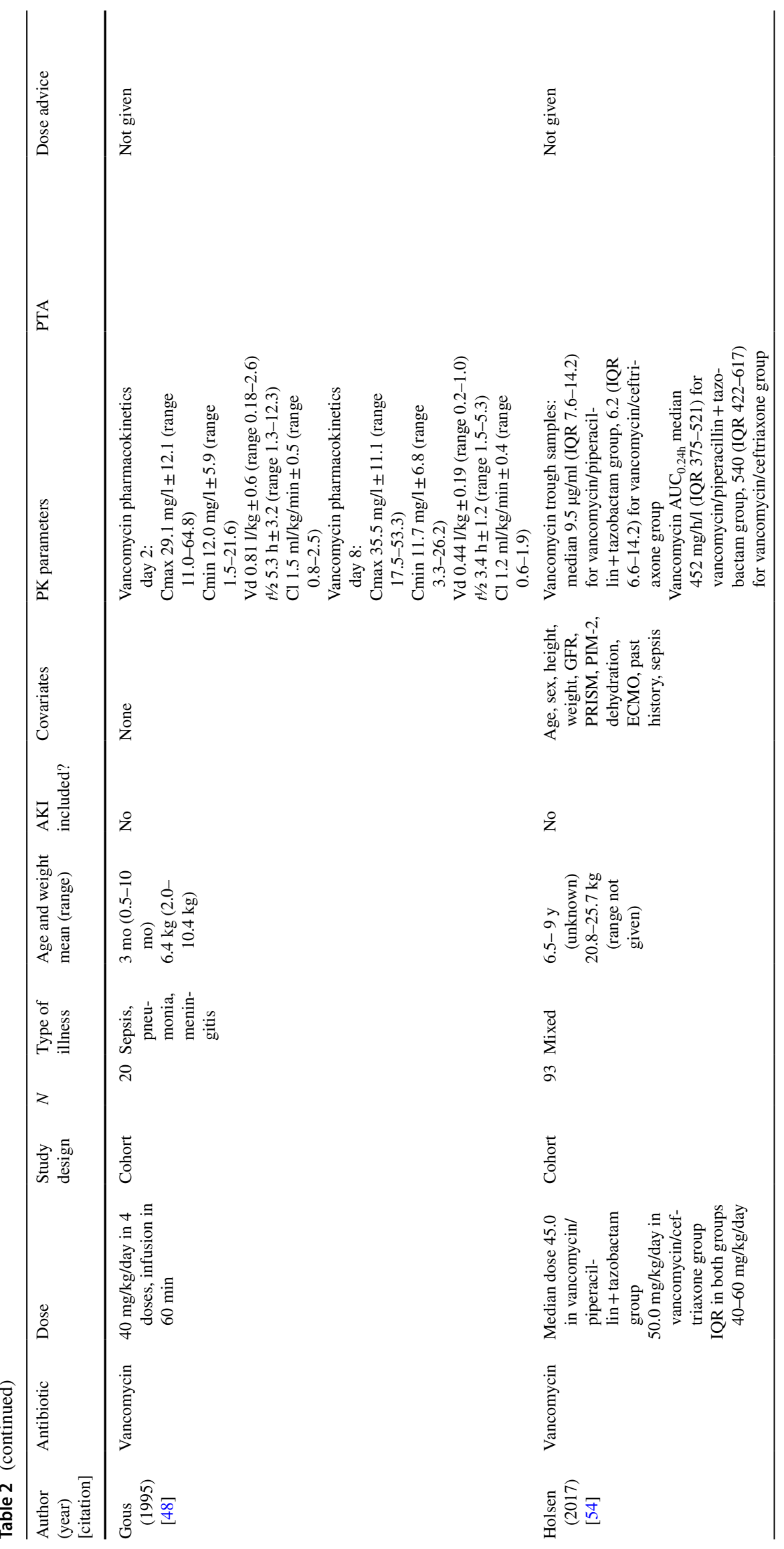




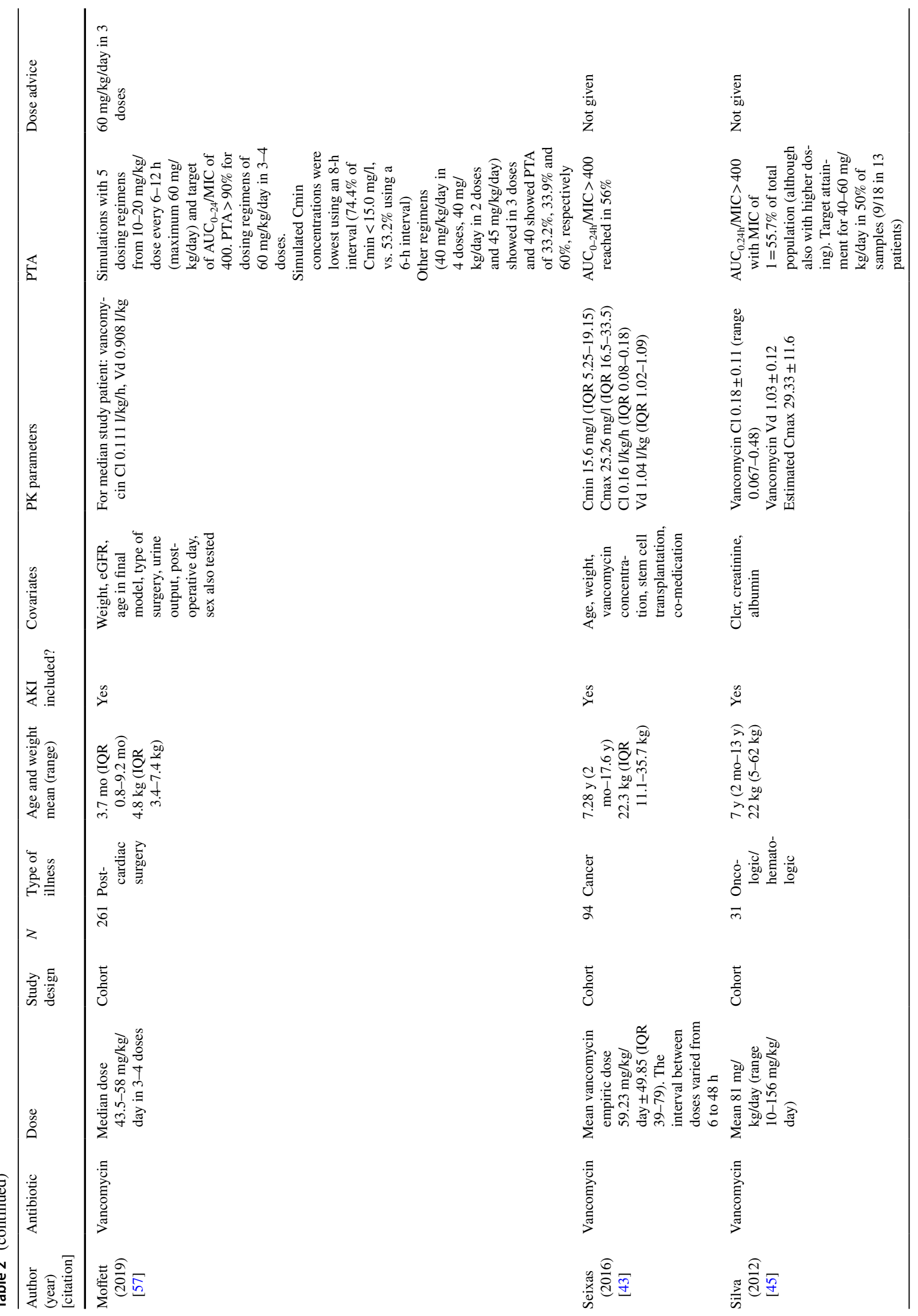




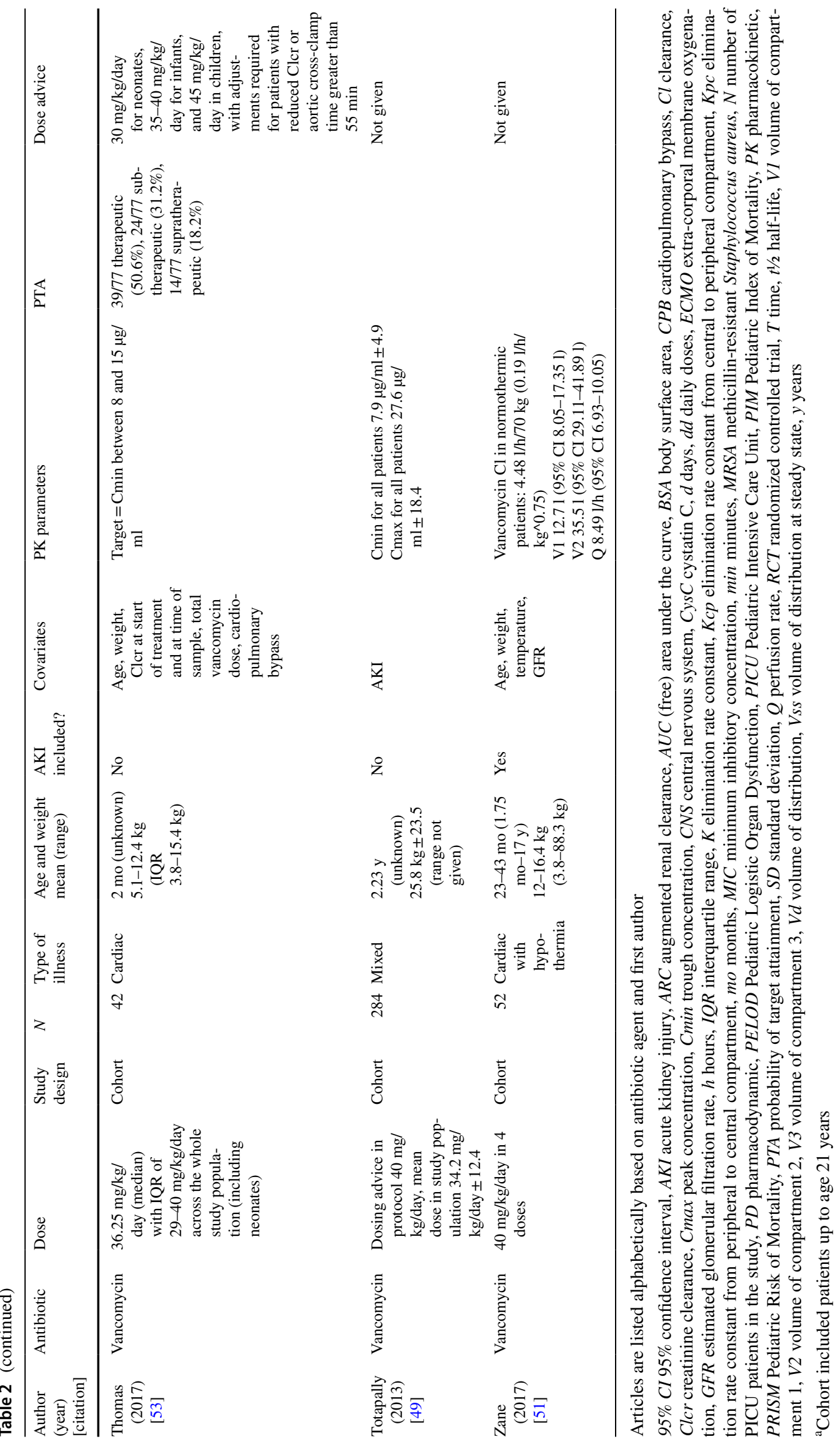


Prolonged infusion of $1 \mathrm{~h}$ increased PTA to $25-100 \%$. The authors propose a daily amoxicillin dose of $150 \mathrm{mg} / \mathrm{kg} / \mathrm{day}$ in six doses. Duration of infusion is dependent on renal function, with an extended infusion in children with cystatin $\mathrm{C}$ concentrations $<1 \mathrm{mg} / \mathrm{l}$.

3.1.1.2 Piperacillin and Tazobactam Five studies reported PK-parameters of piperacillin with or without the addition of the $\beta$-lactamase inhibitor tazobactam [3, 23-26]. Median doses used ranged from 300 to $400 \mathrm{mg} / \mathrm{kg} / \mathrm{day}$ in 3-4 doses, with 1 study using a prolonged infusion time of $4 \mathrm{~h}$ [23] and 1 study not reporting exact dosing schedules used in the study [3]. In total 153 patients were included in these 5 different studies, with a median age of $0.8-5$ years and ages ranging from 0.1 to 18 years. Risk of mortality was reported in 1 study [25], with a median PRISM-score of 8 (range 0-40) and median PELOD scores, reported in 2 studies $[25,26]$, ranged from 1 to 10 . Patients with renal dysfunction were largely excluded from analyses, with only 1 study including 1 patient with renal dysfunction within the cohort [26].

Reported median piperacillin Vd ranged from 0.240 to $0.4441 / \mathrm{kg}$ with the study cohort consisting of predominantly septic, neutropenic and/or burn patients showing the highest $\mathrm{Vd}$ [24]. Cl ranged from 0.190 to $0.299 \mathrm{l} / \mathrm{kg} / \mathrm{h}$. Patients from the cohort with the lowest median piperacillin $\mathrm{Cl}$ still had a particularly high median eGFR of $142 \mathrm{ml} / \mathrm{min} / 1.73 \mathrm{~m}^{2}$ based on serum creatinine[26].

Four of the 5 studies used a PopPK approach and data was best described by a 2-compartment model in 2 studies [24, 25]. In 2 other studies a 1-compartment model best fitted the data, probably because of the use of an extended infusion time [23] or a lack of samples in the distribution phase [26]. All models included weight as a covariate for $\mathrm{Vd}$ and/or $\mathrm{Cl}$. Additional covariates that were included in the final models of these studies were post-menstrual age with a maturation coefficient [25] and eGFR [26] as a covariate for piperacillin $\mathrm{Cl}$ and PELOD-2 scores for Vd [26]. Nichols et al. [23] included gender as a covariate in their final model for tazobactam $\mathrm{Cl}$. Other covariates that were tested for significance but were not included in the final models include cystatin $\mathrm{C}$ based eGFR, PRISM-scores, reason for admission, and co-medication [25].

Target attainment of piperacillin was tested for multiple targets and dosing schemes using Monte Carlo simulations in all four modelling studies. Three of these four used the same target of fT > MIC of 50\% against an MIC of $16 \mathrm{mg} / \mathrm{l}$, reflecting the clinical breakpoint of Pseudomonas aeruginosa [23-25]. Simulations in all studies concluded extended infusion over $>1 \mathrm{~h}$ is needed to reach a PTA of $>90 \%$, but proposed daily piperacillin doses varied, ranging from $300 \mathrm{mg} / \mathrm{kg} /$ day by Nichols et al. up to $600 \mathrm{mg} / \mathrm{kg} /$ day by Béranger et al.

\subsubsection{Cephalosporins}

3.1.2.1 Cefotaxime While three studies were found reporting cefotaxime PK in critically ill children [27-29], most children in the study by Von Hattingberg et al. were neonates, with only two patients $>1$ month of age included in the PK analysis [27]. Doses used varied from 100 to $300 \mathrm{mg} / \mathrm{kg} /$ day in $3-4$ daily doses, with patients $>50 \mathrm{~kg}$ receiving adult doses of three daily doses of $1000 \mathrm{mg}$ in the study by Béranger et al. [28]. Although the exact reason for admission was only clear from the study by Hartman et al. [29], organ dysfunction scores and length of PICU stay was reported in two studies [28, 29]. Organ dysfunction scores and disease severity were highest among the meningococcal septic shock patients studied by Hartman et al. PELOD scores were included in both the model building and validation cohorts by Béranger et al. [28].

$\mathrm{Vd}$ and $\mathrm{Cl}$ were reported by Von Hattingberg and Béranger et al. For the typical study patient (weighing $10.9 \mathrm{~kg}$ and 23.7 months of age) in the study by Béranger the median $\mathrm{Vd}$ and $\mathrm{Cl}$ were $0.31 \mathrm{l} / \mathrm{kg}$ and $0.334 \mathrm{l} / \mathrm{kg} / \mathrm{h}$, respectively. The authors used allometric scaling based on both body weight and postnatal age to predict individual cefotaxime $\mathrm{Cl}$. The two patients in the study by Von Hattingberg et al., one with and one without kidney injury, had a Vd of 0.16 and $0.31 \mathrm{l} / \mathrm{kg}$ and $\mathrm{Cl}$ of 0.109 and $0.4791 / \mathrm{kg} / \mathrm{h}$, respectively. Elimination $t^{1 / 2}$ of cefotaxime were similar in both studies, ranging from 0.34 to $1.15 \mathrm{~h}$ in the study by Béranger et al. and 0.46-1.02 $\mathrm{h}$ for the two patients without and with kidney injury by Von Hattingberg et al.

Both studies used a one-compartment model to describe PK parameters, possibly due to the limited sampling strategy with a median of two samples per patient. The co-variates studied by Béranger et al. include weight, age, serum creatinine, and PELOD-scores [28]. Only weight and age were included in the final model as significant covariates on $\mathrm{Cl}$ and/or Vd. Monte-Carlo simulations were performed with several dosing regimens to identify the needed dose to reach the target of fT $>$ MIC and fT $>4 x$ MIC of $100 \%$, against MIC values of $0.5 \mathrm{mg} / \mathrm{l}$. The authors concluded that intermittent dosing without prolonged infusion, for patients over 1 month of age, would require a daily dose of $4500 \mathrm{mg} / \mathrm{kg}$ to reach these targets. However, continuous dosing of $100 \mathrm{mg} /$ $\mathrm{kg} /$ day would be sufficient to reach adequate targets in all age groups. Therefore, the authors advised to use continuous dosing for optimal cefotaxime dosing in critically ill children.

The study by Hartman et al. found a slightly higher percentage of target attainment (71.3\%) for the PD-target of $\mathrm{fT}>4 \mathrm{xMIC}$ of $100 \%$ against an MIC of $0.5 \mathrm{mg} / \mathrm{l}$ using standard doses. Higher MIC values of 1 and $4 \mathrm{mg} / \mathrm{l}$, that might be more clinically relevant, showed a lower target attainment of $55.1 \%$ and $14.7 \%$, respectively. The authors 
state that this is a best-case scenario of target attainment, as samples were randomly drawn across the dosing interval and no PK model to simulate actual probability of target attainment was developed.

3.1.2.2 Cefuroxime We identified only one study on cefuroxime PK in PICU patients [30], 15 patients in total, including 4 non-critically ill patients with pharyngitis. The 11 PICU patients were divided in 2 groups: a severely ill group of 5 PICU patients not requiring mechanical ventilation, and a very severely ill group with 6 patients requiring mechanical ventilation. No severity of illness scores were provided. All patients were treated with a cefuroxime dose of $400 \mathrm{mg} /$ $\mathrm{kg}$ /day in four doses as intermittent infusions over $30 \mathrm{~min}$.

Both $\mathrm{Vd}$ and $\mathrm{Cl}$ were higher in mechanically ventilated patients compared to control and PICU patients that did not require mechanical ventilation. Even though differences between $\mathrm{Vd}$ and $\mathrm{Cl}$ between control and non-intubated PICU patients were minimal, $t^{1 / 2}$ of cefuroxime was longer in both critically ill groups compared to the control patients (1.0-1.3 h vs. $0.5 \mathrm{~h})$.

The study used both 1- and 2-compartment models to describe the obtained PK-data, for each individual patient. In the majority of patients (8/11) a 2-compartment model gave the best fit of the observed data. No dosing advice was given to account for these PK changes in critically ill patients.

3.1.2.3 Cefazolin Three cefazolin studies were included in our review, all conducted before, during or after cardiopulmonary bypass (CPB) [19, 20, 31]. One study included only patients under $10 \mathrm{~kg}$ bodyweight and up to 2.6 years of age [31] while the other 2 studies basically covered the whole pediatric age range from birth to 16 years old [19, 20]. Used cefazolin doses varied between the 3 studies with de Cock et al. and Cies et al. both using $25 \mathrm{mg} / \mathrm{kg} / \mathrm{dose}$ preoperatively and during CPB and Haessler et al. using $40 \mathrm{mg} / \mathrm{kg}$ preoperatively and $105 \mathrm{mg} / \mathrm{kg} /$ day in 3 doses in the days after surgery. Interestingly, Cies et al. also added a dose of $25 \mathrm{mg} / \mathrm{kg}$ bodyweight cefazolin to the CPB primer solution to ensure stable antibiotic levels during CBP.

In the study by Haessler et al. cefazolin concentrations during and after surgery showed a mean Cmax of 166 mg/l and a steady-state Cmin of $15 \mathrm{mg} / \mathrm{l}$ was reached [31]. Elimination rate constants of cefazolin were significantly lower during CBP $(0.331 / \mathrm{h})$ and significantly higher after surgery $(1.429 / \mathrm{h})$ compared to before surgery $(0.738 / \mathrm{h})$. In addition, the Vd increased during CBP due to increased blood volume during extracorporeal circulation $(0.3571 / \mathrm{kg}$ compared to $0.191 \mathrm{l} / \mathrm{kg}$ before surgery). After surgery $\mathrm{Vd}$ returned to baseline values $(0.127 \mathrm{l} / \mathrm{kg})$. This increase in $\mathrm{Vd}$ during CPB was also seen by de Cock et al. who used a CPBcompartment ranging from 150 to $1000 \mathrm{ml}$ in their model. The mean population values for $\mathrm{Cl}$ and $\mathrm{Vd}$ in their model,
$0.229 \mathrm{l} / \mathrm{kg} / \mathrm{h}$ and $0.635 \mathrm{l} / \mathrm{kg}$ respectively, show a comparable elimination rate constant but a higher $\mathrm{Vd}$, possibly due to including older patients in their cohort. PK parameters in the study by Cies et al. are hard to compare with the other studies due to their alternative dosing strategy, giving markedly lower clearance values of roughly $0.0005 \mathrm{l} / \mathrm{kg} / \mathrm{h}$. Volume of distribution values found by Cies et al. were comparable with those found by de Cock et al., except for the oldest age group of 4-16 years old.

Both de Cock et al. [19] and Cies et al. [20] used a PopPK approach by using a 2-compartment and 1-compartment model, respectively. Both models included bodyweight and age in their final models, with de Cock et al. also including eGFR as a covariate for $\mathrm{Cl}$ and albumin concentrations as a covariate for protein binding. Dosing simulations were performed only by de Cock et al., using a PD-target of 50-100\% $\mathrm{fT}>\mathrm{MIC}$ against MICs ranging from 0.125 to $16 \mathrm{mg} / \mathrm{l}$. They conclude that the standard dosing regimen of $25 \mathrm{mg} / \mathrm{kg} / \mathrm{dose}$ shows a PTA of roughly $50 \%$, while the optimal dosing regimen that used doses up to $40 \mathrm{mg} / \mathrm{kg} /$ dose showed a PTA of 88-99\%. Cies et al. conclude that adding cefazolin to the CPB primer solution ensures stable, adequate concentrations of cefazolin throughout surgery, but more research is needed.

3.1.2.4 Ceftaroline Cies et al. mentioned TDM outcomes in 7 patients treated with non-standard (higher) doses of $60 \mathrm{mg} / \mathrm{kg} / \mathrm{day}$ in 4 doses in a paper on multiple antibiotics [3]. The majority of patients did not require an additional dose alteration to achieve target attainment.

Cies and colleagues also published a case series of 7 patients treated with ceftaroline, presumably the same patients as mentioned in the previous publication, which is the only PK-data of ceftaroline we identified [32]. All patients were treated for a suspected MRSA infection and patients with an estimated creatinine clearance below $60 \mathrm{ml} /$ $\min / 1.73 \mathrm{~m}^{2}$ were excluded. Patients started with a nonstandard dose of 54-60 mg/kg/day, but dosing regimens were altered to reach the target of fT $>4-6 \times \mathrm{MIC}$ for $40 \%$ of the dosing interval, with MICs ranging from 0.38 to $1 \mathrm{mg} / \mathrm{l}$. Individual PK-parameters for several dosing regimens are mentioned, but for the starting regimen median $\mathrm{Vd}, \mathrm{Cl}$ and $t^{1 / 2}$ were $0.41 \mathrm{l} / \mathrm{kg}, 0.218 \mathrm{l} / \mathrm{kg} / \mathrm{h}$ and $1.3 \mathrm{~h}$. The authors compare their observed PK-parameters to the PK-parameters for healthy pediatric patients in the package insert. The patients in the study showed a higher median $\mathrm{Vd}(0.41 \mathrm{l} /$ $\mathrm{kg})$, higher $\mathrm{Cl}(0.218 \mathrm{l} / \mathrm{kg} / \mathrm{h})$ and shorter $t^{1 / 2}(1.3 \mathrm{~h})$ than the package insert estimates, which were $0.28 \mathrm{l} / \mathrm{kg}, 0.138 \mathrm{l} /$ $\mathrm{kg} / \mathrm{h}$ and $2.7 \mathrm{~h}$, respectively [33]. All patients required a dose alteration or a non-FDA-approved dose to reach target attainment, and all patients eventually were cured from their MRSA infections. The authors advise a 6-h dosing 
interval in bloodstream infections, pneumonia or meningitis with MRSA and a dose of $15 \mathrm{mg} / \mathrm{kg} / \mathrm{dose}$ in patients with increased Vd.

\subsubsection{Carbapenems}

3.1.3.1 Meropenem For meropenem 1 case report and 1 PopPK model, both by Cies et al., were identified [34, 35]. The case report describes a 2-year-old girl with a Serratia marcescens ventriculitis [34]. She was treated with $150 \mathrm{mg} /$ $\mathrm{kg}$ /day intermittent infusions for $30 \mathrm{~min}$, but this resulted in undetectable meropenem plasma concentration $4 \mathrm{~h}$ after dosing. Eventually she was successfully treated with an increased dose of meropenem of $200 \mathrm{mg} / \mathrm{kg} / \mathrm{day}$ as a continuous infusion, reaching plasma concentrations of $13 \mathrm{mg} / \mathrm{l}$ and CSF concentrations of $0.5 \mathrm{mg} / \mathrm{l}$. The calculated $\mathrm{Cl}$ of this patient was $0.612 \mathrm{l} / \mathrm{kg} / \mathrm{h}$. The authors claim this clearance is higher than reported values in healthy adults and critically ill children on extracorporeal membrane oxygenation, but exact numbers are not reported.

The 2017 PopPK model by Cies et al. included data from 9 patients treated with doses ranging from 40 to $200 \mathrm{mg} / \mathrm{kg} /$ day [35]. Most patients received intermittent infusions in $30 \mathrm{~min}, 2-4$ times per day. One patient was treated with continuous infusion of $200 \mathrm{mg} / \mathrm{kg} /$ day and one patient received $100 \mathrm{mg} / \mathrm{kg} /$ day in 2 daily doses as prolonged infusions for $2 \mathrm{~h}$. Median (range) age of patients was 2 (1-9) years. No patients with renal dysfunction were included, and the median eGFR was $168 \mathrm{ml} / \mathrm{min} / 1.73 \mathrm{~m}^{2}$, indicating possible ARC within the study population.

A roughly 2 times larger $\mathrm{Vd}(0.78 \mathrm{l} / \mathrm{kg})$ and slightly higher $\mathrm{Cl}(0.419 \mathrm{l} / \mathrm{kg} / \mathrm{h})$ were described in this cohort by Cies et al. [35]. compared to other studies in clinically stable pediatric patients by Du et al. [36] and Blumer et al. [37] (Vd 0.2-0.43 1/kg and $\mathrm{Cl} 0.18-0.34 \mathrm{l} / \mathrm{kg} / \mathrm{h}$, respectively).

After a sparse sampling scheme with a total of 16 meropenem concentrations a Pmetrics 2-compartment PopPK model was used to estimate PK. Weight, age and creatinine clearance were considered to be significant covariates for $\mathrm{Vd}$ and/or $\mathrm{Cl}$.

Target attainment of $40 \% \mathrm{fT}>$ MIC was only reached in simulations of dosing regimens with prolonged or continuous infusion of $120-160 \mathrm{mg} / \mathrm{kg} / \mathrm{day}$, with MICs ranging from 0.25 up to $2 \mathrm{mg} / \mathrm{l}$. Target attainment of $80 \% \mathrm{fT}>$ MIC was only reached with continuous infusion for MICs up to $2 \mathrm{mg} / \mathrm{l}$. For higher MICs, the PTA was below $90 \%$ in all simulations.

3.1.3.2 Imipenem Gianonni et al. studied imipenem PK in 19 critically ill children ranging from 9 days to 12 years of age [38]. Patients were treated with $100 \mathrm{mg} / \mathrm{kg} /$ day in 3-4 daily 30-min infusions. The median (range) PRISM score was 9 (0-23) and although patients with renal dys- function were included, the exact number of patients with impaired renal function is unclear.

A non-compartmental analysis was performed to estimate $\mathrm{Cl}, t^{1 / 2}$ and $\mathrm{Vd}$ of imipenem in critically ill children after the first dose and at steady state. All PK-parameters slightly increased from first dose to steady state. The authors compared their findings to other studies in (noncritically ill) children with imipenem. PK-parameters were within the reported values for pediatric patients, with a slightly lower $\mathrm{Cl}$, higher $\mathrm{Vd}$ and a longer $t^{1 / 2}$ in critically ill patients. Moreover, the correlation between several covariates and the PK-parameters was tested, including age, weight, creatinine clearance, albumin, lactate, disease severity, blood pressure and heart rate. Eventually, $\mathrm{Cl}$ parameters correlated best with creatinine clearance, mean arterial pressure and lactate acidosis, although it is unclear how creatinine clearance was measured or estimated.

\subsubsection{Other Penicillins}

3.1.4.1 Aztreonam The only PK-data on aztreonam, a broad-spectrum monobactam antibiotic agent, is found within a case-report by Cies et al. [39]. In this case-report the authors describe a case of a 16-year-old tetraplegic patient with a pneumonia caused by a multi-resistant Pseudomonas aeruginosa [39]. This pathogen was susceptible to aztreonam against an MIC of $6 \mathrm{mg} / \mathrm{l}$ and the patient was treated with aztreonam $8 \mathrm{~g}$ /day in 4 prolonged infusions of $4 \mathrm{~h}$. $\mathrm{Cl}$ was $0.138 \mathrm{l} / \mathrm{kg} / \mathrm{h}$, almost double of the adult $\mathrm{Cl}$ values reported in the package insert $(0.078 \mathrm{l} / \mathrm{kg} / \mathrm{h})$ [40]. The used dose resulted in plasma concentrations above $6 \mathrm{mg} / \mathrm{l}$ for at least $40 \%$ of the time with a Cmax of $71 \mathrm{mg} / \mathrm{l}$.

\subsection{Glycopeptide Antibiotics}

\subsubsection{Vancomycin}

A total of 17 studies reporting PK-parameters of vancomycin in critically ill children were identified by the search, with more than 1000 PICU patients included in total over the whole pediatric age range [41-57]. Most studies included a mixed population, but also specific populations (such as patients with hematologic/oncologic [43, 45], cardiac [51, 53, 56, 57], traumatic [50] and infectious diseases $[44,48]$ ) being studied separately. Four studies [42, $43,46,48]$ were prospective PK studies and the remaining 13 studies were based on TDM data.

Most studies used intermittent dosing with daily doses of vancomycin ranging from 30 to $60 \mathrm{mg} / \mathrm{kg} / \mathrm{day}$, with only 1 study reporting higher mean doses $(81 \mathrm{mg} / \mathrm{kg} /$ day $)$ [45] and 1 study not mentioning the dose at all [41]. Two studies 
reported data on continuous dosing schedules, using a loading dose of $15 \mathrm{mg} / \mathrm{kg}$ and a maintenance dose of $40-45 \mathrm{mg} /$ $\mathrm{kg}$ over $24 \mathrm{~h}[42,55]$.

Vancomycin is predominantly cleared by glomerular filtration and is also associated with nephrotoxicity, therefore 7 studies mainly reported findings on the effect or occurrence of acute kidney injury (AKI) and/or ARC in patients treated with vancomycin $[41,44,49,50,52,54,56]$. Several studies, including 2 studies with over 250 patients, reported conflicting results regarding vancomycin $\mathrm{Cmin}$ in patients with and without AKI. Bonazza et al. [41] showed increased Cmin in patients with AKI whereas Totapally et al. [49] and Holsen et al. [54] both found no significant differences in Cmin and/ or Cmax between patients with and without AKI. To identify whether higher vancomycin Cmin lead to kidney injury Cies et al. performed a retrospective study comparing 2 groups, with either a high (15-20 mg/l) or low (10-15 mg/l) target Cmin of vancomycin [44]. The incidence of AKI was not significantly different between these 2 groups.

ARC is the main focus of 2 studies, 1 case report [50] and 1 cohort study with 250 patients aged $0-21$ years old [52]. ARC was defined by an estimated creatinine clearance of $>150$ and $>160 \mathrm{ml} / \mathrm{min} / 1.73 \mathrm{~m}^{2}$ by Goboova et al. [50] and Avedissian et al. [52], respectively. The patient in the case report required a doubling and tripling of the initial dose (from $2 \mathrm{~g} /$ day in 2 doses to $4-6 \mathrm{~g} /$ day in 2 doses) to reach therapeutic Cmin of 10-15 mg/l. Avedissian et al. found 29 patients with ARC, $12 \%$ of their total cohort [52]. PK data were analyzed using pop-PK with NONMEM. Patients with ARC were significantly older and had lower baseline serum creatinine levels. PK-parameters for vancomycin were significantly different in patients with ARC: they had lower median $\mathrm{Cmin}$, higher median $\mathrm{Cl}$, larger median $\mathrm{Vd}$ and a shorter median $t^{1 / 2}$. Subtherapeutic drug concentrations were more common in patients with ARC compared to patients without ARC (79\% and 58\%, respectively), but this difference was not statistically tested. Both age and serum creatinine were independent covariates for $\mathrm{Cl}$. Weight was the only independent covariate for $\mathrm{Vd}$.

Of the 17 vancomycin articles, 8 reported $\mathrm{Cmin}$ and/or Cmax as the only PK-parameters. Six of these have already been discussed in the previous paragraphs regarding AKI or ARC $[41,44,49,50,54,56]$. The 2 remaining articles, by Glover et al. [47] and Thomas et al. [53], both included patients with a normal renal function at the start of treatment. Both studies analyzed PK-parameters in steady state after the initial dose, while Glover et al. also looked at the final doses used after TDM. After the initial therapy with a mean dose of $47.3 \mathrm{mg} / \mathrm{kg} /$ day mean Cmin were $6.2 \mathrm{mg} / \mathrm{l} \mathrm{on}$ average [47]. Mean doses after TDM were roughly $60 \mathrm{mg} /$ $\mathrm{kg} /$ day, resulting in higher mean Cmax and Cmin of 26.0 and $7.8 \mathrm{mg} / \mathrm{l}$, respectively. The authors advised to use $60 \mathrm{mg} /$ $\mathrm{kg} /$ day in critically ill patients with normal renal function to ensure optimal target attainment, but do not specify the desired target concentrations. Thomas et al. included both neonates, infants and children in their study [53]. They found that roughly $50 \%$ (39 of 77) of patients reach adequate $\mathrm{Cmin}$ (using a dose of $30-40 \mathrm{mg} / \mathrm{kg} / \mathrm{day}$ and a target Cmin between 8 and $15 \mathrm{mg} / \mathrm{l}$ ) and sub- and supratherapeutic concentrations in $31.2 \%$ and $18.2 \%$ of patients, respectively. Multivariable regression analysis identified age, weight and creatinine clearance at the start of treatment as significant co-variates for vancomycin $\mathrm{Cmin}$.

Cmin measurements are mainly used for TDM as a surrogate parameter of the true PD target of vancomycin used in adults (AUC/MIC > 400) and is commonly extrapolated to pediatric patients. Several studies determined, simulated or estimated AUC/MIC in their analysis $[42,43,45,46$, 54, 55, 57]. Giachetto et al. reported vancomycin $\mathrm{AUC}_{0-24 \mathrm{~h}} /$ MIC on both day 1 , using an initial dose of $33-45 \mathrm{mg} / \mathrm{kg} /$ day, and after TDM on day 3 for MICs of 1 and $2 \mathrm{mg} / \mathrm{l}$ [46]. Mean AUCs for day 1 and day 3 were $364 \mathrm{mg} / \mathrm{l} / \mathrm{h}$ for both days, with roughly $50 \%$ of patients reaching the target of AUC/MIC $>400$ for the MIC of $1 \mathrm{mg} / \mathrm{l}$ and $5-7 \%$ for the MIC of $2 \mathrm{mg} / \mathrm{l}$. Simulations with several dosing regimens in the study by Moffett et al. [57] showed a target attainment of $>90 \%$ for regimens using $60 \mathrm{mg} / \mathrm{kg} / \mathrm{day}$ in 3-4 doses and a target attainment ranging from 33.2 to $60 \%$ for dosing regimens with a lower daily dose of $40-45 \mathrm{mg} / \mathrm{kg} /$ day in $2-4$ doses. Other studies reporting AUC/MIC data all reported similar percentages of target-attainment of approximately $50 \%$, with only Genuini et al. [55] (using a continuous dose of $45 \mathrm{mg} / \mathrm{kg} /$ day) reporting lower target attainment of $17-32 \%$. De Cock et al. also included 3 patients with continuous dosing, but no separate PK-parameters for these 3 patients were presented [42]. The study by de Cock et al. was the only study including free AUC/MIC values, with a target of fAUC $_{0-24 \mathrm{~h}} / \mathrm{MIC}>200$ assuming an unbound fraction of $50 \%$ [42]. The measured unbound fraction of vancomycin in their study was higher than this assumption (71.1\%). The majority of patients $(83 \%)$ reached this unbound vancomycin target using a dose of $60 \mathrm{mg} / \mathrm{kg} /$ day. When using Cmin between 5 and $10 \mathrm{mg} / \mathrm{l}$ as a surrogate target, only $8 \%$ of patients reach this target, questioning the validity of this surrogate target in critically ill pediatric patients.

Other PK-parameters presented in several studies include $\mathrm{Cl}$ and $\mathrm{Vd}$ in 7 studies [43, 45, 46, 48, 51, 52, 57], with 2 studies reporting data on vancomycin $t^{1 / 2}[48,52]$. Mean $\mathrm{Vd}$ within each study ranged from 0.44 to $1.04 \mathrm{l} / \mathrm{kg}$, with a median $\mathrm{Vd}$ among studies of $0.77 \mathrm{l} / \mathrm{kg}$. Mean $\mathrm{Cl}$ in each study ranged from 0.072 to $0.19 \mathrm{l} / \mathrm{kg} / \mathrm{h}$, with a median of $0.154 \mathrm{l} / \mathrm{kg} / \mathrm{h}$ found among studies. Avedissian et al. and Gous et al. both reported a similar $t^{1 / 2} 2(3.4$ and $3.62 \mathrm{~h}$, respectively) [48, 52]. 


\subsubsection{Teicoplanin}

Three prospective studies describe teicoplanin PK in critically ill children with ages ranging from 7 days to a maximum of 12 years old $[18,58,59]$. Doses used in studies varied, with 2 studies $[58,59]$ using 3 loading doses of $10 \mathrm{mg} /$ $\mathrm{kg}$ teicoplanin every $12 \mathrm{~h}$ and afterwards a maintenance dose of $10 \mathrm{mg} / \mathrm{kg}$ every $24 \mathrm{~h}$. The study by Lukas et al. was designed as a randomized controlled trial where patients in the other study arm received a higher maintenance dose of $15 \mathrm{mg} / \mathrm{kg}$ every $24 \mathrm{~h} \mathrm{[58].} \mathrm{One} \mathrm{study,} \mathrm{by} \mathrm{Reed} \mathrm{et} \mathrm{al.,} \mathrm{used}$ lower daily doses of $6 \mathrm{mg} / \mathrm{kg}$ in patients undergoing cardiac or head surgery, without information on whether a loading dose was given [18].

Sanchez et al. described 21 patients, mainly post cardiac surgery, including 1 patient with renal dysfunction with an eGFR of $55 \mathrm{ml} / \mathrm{min} / 1.73 \mathrm{~m}^{2}$ [59]. A total of 127 samples were drawn, with a full PK-curve after the first dose of teicoplanin and Cmin 1, 2, 3 and 7 days after the first dose. PK-parameters were determined by a non-compartmental analysis using an open 2-compartment model. Mean Cmax values at $0.5 \mathrm{~h}$ were $26.2 \mathrm{mg} / \mathrm{l}, \mathrm{Cmin}$ at steady state were $5.8 \mathrm{mg} / \mathrm{l}$ and mean AUC was $224.5 \mathrm{mg} / \mathrm{l} / \mathrm{h}$. Vd at steady state was $1.02 \mathrm{l} / \mathrm{kg}$ and total $\mathrm{Cl}$ was $0.045 \mathrm{l} / \mathrm{kg} / \mathrm{h}$ and a terminal $t^{1 / 2}$ of $17.41 \mathrm{~h}$. PK-parameters are presented without an indication of variance, which makes extrapolation to other cohorts difficult. The authors used a target of $>10 \mathrm{mg} / \mathrm{l}$, which was reached in only $11 \%$ of Cmin samples. Teicoplanin concentrations and PK-parameters did not differ between patients under 3 months, 3-12 months and over 12 months of age although it is unclear how many patients were represented in each age group and the overall group size was relatively small.

As mentioned before, Lukas et al. performed a randomized controlled trial with half of the patients receiving a larger maintenance dose [58]. However, no significant differences in teicoplanin concentrations were observed between these 2 dosing strategies. The authors did find a significant difference between young infants (aged $<12$ months) and older children ( $>12$ months), with a lower target attainment in older children (65\%) compared to young infants (92\%). Further analyses in this study focused on the differences in PK-parameters between these 2 age groups, regardless of the randomized maintenance dose. Children $>12$ months had a higher $\mathrm{Cl}$, larger $\mathrm{Vd}$ and longer $t^{1} / 2(3.9 \mathrm{l} / \mathrm{kg} / \mathrm{h}, 0.29 \mathrm{l} / \mathrm{kg}$ and $9.32 \mathrm{~h}$, respectively) compared to younger infants (1.05 l/ $\mathrm{kg} / \mathrm{h}, 0.09 \mathrm{l} / \mathrm{kg}, 8.1 \mathrm{~h}$, respectively). The authors concluded that for younger infants 3 loading doses of $5 \mathrm{mg} / \mathrm{kg}$ every $12 \mathrm{~h}$ followed by $4 \mathrm{mg} / \mathrm{kg}$ once daily would be sufficient to reach adequate target attainment. For older children, the authors advise 3 loading doses of $10 \mathrm{mg} / \mathrm{kg}$ every $12 \mathrm{~h}$ and subsequently $8 \mathrm{mg} / \mathrm{kg}$ once daily as maintenance dose.
Interestingly, this is a lower maintenance dose than used in the study population that showed limited target attainment.

Reed et al. [18] included 12 patients with a median age of 6 years; 11 after cardiac surgery and 1 with head surgery. Teicoplanin PK-parameters were determined after the 1st and 5th dose in a 3-compartment model using PCNONLIN. Cmax and Cmin were $39.3 \mathrm{mg} / \mathrm{l}$ and $1.8 \mathrm{mg} / \mathrm{l}$, respectively, after the first dose and $40.8 \mathrm{mg} / \mathrm{l}$ and $3.1 \mathrm{mg} / \mathrm{l}$, after the fifth dose. After the first dose, $\mathrm{Vd}$ was $0.46 \mathrm{l} / \mathrm{kg}$ and total $\mathrm{Vd}$ in steady state, after the 5 th dose, was $0.561 / \mathrm{kg}$. Total body $\mathrm{Cl}$ after the first dose was $2.38 \mathrm{l} / \mathrm{kg} / \mathrm{h}$, with renal $\mathrm{Cl}$ contributing for $1.09 \mathrm{l} / \mathrm{kg} / \mathrm{h}$ of total $\mathrm{Cl}$. After the 5 th dose only total body $\mathrm{Cl}$ was determined at $2.19 \mathrm{l} / \mathrm{kg} / \mathrm{h}$. Terminal $t^{1 / 2}$ was 11.3 and $16.3 \mathrm{~h}$ after the first and fifth dose, respectively. No additional covariates were identified for their influence on teicoplanin PK. The authors recommended using higher doses (than the $6 \mathrm{mg} / \mathrm{kg}$ once daily used in this study) of teicoplanin in critically ill children, $8 \mathrm{mg} / \mathrm{kg}$ every $12 \mathrm{~h}$ to reach Cmin of $>10 \mathrm{mg} / \mathrm{l}$ and $15 \mathrm{mg} / \mathrm{kg}$ every $12 \mathrm{~h}$ for $\mathrm{Cmin}>20 \mathrm{mg} / \mathrm{l}$ (e.g. in case of endocarditis).

\subsection{Aminoglycoside Antibiotics}

\subsubsection{Gentamicin}

Haessler et al., also determined gentamicin concentrations before, during and after cardiac surgery in children $<10 \mathrm{~kg}$ [31]. During surgery, gentamicin Cmax reached $20.8 \mathrm{mg} / \mathrm{l}$ and mean Cmin on day 2 and 3 were 1.1 (SD 0.5) $\mathrm{mg} / \mathrm{l}$ and 0.8 (SD 0.4) mg/l, respectively. Like the results for cefazolin, as discussed above, $k$ for gentamicin declined during surgery $(0.336 / \mathrm{h})$ compared to baseline $(0.962 / \mathrm{h})$. However, contrary to cefazolin data, the $k$ remained significantly lower after surgery $(0.188 / \mathrm{h})$. Vd also showed a different pattern for gentamicin than cefazolin. Vd increased during surgery $(0.237 \mathrm{l} / \mathrm{kg}$ before surgery to $0.400 \mathrm{l} / \mathrm{kg}$ during surgery), in concordance with cefazolin data. However, $\mathrm{Vd}$ remained increased after surgery $(0.624 \mathrm{l} / \mathrm{kg})$ compared to baseline, and was even larger than the $\mathrm{Vd}$ during surgery.

Three other studies report PK-parameters of gentamicin in critically ill children [60-62]. The study by Kraus et al. [62] used a dosing scheme of multiple daily doses, whereas the other 2 studies used a single daily dose [60, 61]. Kraus et al. used doses ranging from 1.8 to $3.1 \mathrm{mg} / \mathrm{kg} /$ dose with 2-3 daily doses, with the majority of patients (39/44) receiving 3 daily doses [62]. The group of 44 patients was divided in 2 groups based on the number of gentamicin Cmax and Cmin concentrations that were available. The group with only 1 set of Cmax and Cmin concentrations ( $n=$ unknown) was used to determine population-based PK-parameters, which were validated in the other group of patients with multiple sets of Cmax and Cmin concentrations. The population-based values for $\mathrm{Vd}, \mathrm{Cl}$ and $t^{1 / 2}$ were $0.416 \mathrm{l} /$ 
$\mathrm{kg}, 0.114 \mathrm{l} / \mathrm{kg} / \mathrm{h}$ and $2.8 \mathrm{~h}$, respectively. PK-parameters for the validation group with multiple sets of Cmax and Cmin concentrations were not significantly different from these population-based values. There was no correlation between age or post-operative status and PK-parameters. Dosing simulations were performed using the population-based values, with $\mathrm{Cmax}=7 \mathrm{mg} / \mathrm{l}$ and $\mathrm{Cmin}=1 \mathrm{mg} / \mathrm{l}$ as predefined target. A mean daily dose of $9.1 \mathrm{mg} / \mathrm{kg} / \mathrm{day}$ (range $5.2-14.8 \mathrm{mg} / \mathrm{kg}$ / day) divided in 2-6 daily doses was predicted to reach these target concentrations.

Lopez et al. used a dosing scheme of $8 \mathrm{mg} / \mathrm{kg}$ every 24-36 h [61]. The actual dose used in the study by Zakova et al. is unknown, but Monte-Carlo simulations for target attainment were performed with a simulated dose of $6 \mathrm{mg} /$ $\mathrm{kg}$ every $24 \mathrm{~h}$ [60]. Both studies used a mixed patient population; with Zakova mainly using younger children, aged up to 21 months and Lopez et al. including older patients up to 14 years old (and including 14 neonatal patients as well that are not included in this review). Both studies included patients with renal dysfunction, $10 \%$ of patients in the study by Lopez et al. required renal replacement therapy, but for both studies it is unclear how many patients actually suffered from any form of renal dysfunction.

Several co-variates were tested for their influence on PK-parameters; both studies identified age and weight as significant co-variates for $\mathrm{Vd}$ and/or $\mathrm{Cl}$. Serum creatinine was correlated with the $k$ in the study by Zakova [60], but was not found to improve the model of Lopez et al. [61]. Other tested co-variates by Zakova et al. were gender, comedication, admission unit, PRISM-scores and serum albumin, with only the admission unit (PICU or Cardiac Critical Care Unit) being significantly correlated with $\mathrm{Vd}$ and $k$ in multiple regression analysis [60].

The 2 measured PK-parameters by Zakova et al. are Vd and the $k$ [60]. Values for Cmax, AUC and the drug-free interval were simulated using Monte-Carlo simulations. Median Vd was $0.39 \mathrm{l} / \mathrm{kg}$ and $k 0.18 / \mathrm{h}$. Using a simulated dose of $6 \mathrm{mg} / \mathrm{kg}$ every $24 \mathrm{~h}$, median Cmax, AUC and drugfree interval values were $17.6 \mathrm{mg} / 1,78.6 \mathrm{mg} / \mathrm{l} / \mathrm{h}$ and $15.2 \mathrm{~h}$. The simulated dosing scheme of $6 \mathrm{mg} / \mathrm{kg}$ resulted in $28.4 \%$ of patients within the Cmax target of 16-20 mg/l (38.8\% below, $32.8 \%$ above), $22.4 \%$ of patients within AUC target of $70-100 \mathrm{mg} / \mathrm{h} / \mathrm{l}$ (37.3\% below, $40.3 \%$ above) and $53.7 \%$ of patients within the drug-free interval target of $4-16 \mathrm{~h}(6 \%$ below, $40.3 \%$ above).

Lopez et al. used non-linear mixed effect modelling to determine population-based PK-parameters in a 2-compartment model [61]. Mean population value for $\mathrm{Cl}$ was normalized for a $70 \mathrm{~kg}$ patient at $2.09 \mathrm{l} / \mathrm{h} / 70 \mathrm{~kg}$, with age and weight being significant co-variates for individual $\mathrm{Cl}$ values. $\mathrm{Vd}$ of the peripheral compartment was fixed at $3.78 \mathrm{I}$ and the volume of the central compartment was $0.35 \mathrm{l} / \mathrm{kg}$. Target attainment was defined as $C \max >16 \mathrm{mg} / \mathrm{l}$ and was determined for different daily doses up to $8 \mathrm{mg} / \mathrm{kg}$ of gentamicin. This target was reached in all non-neonates using a dose of $7-8 \mathrm{mg} / \mathrm{kg}$, but the authors stated that dosing intervals should be extended in younger infants due to age-related changes in renal $\mathrm{Cl}$ and the risk of toxicity in the case of gentamicin accumulation.

\subsubsection{Amikacin}

One randomized controlled trial (RCT) and 2 cohort studies on the PK of amikacin were found [63-65]. The RCT, performed by Marik et al. included 60 pediatric patients $<1$ year of age that were treated with amikacin $20 \mathrm{mg} / \mathrm{kg} /$ day [63]. Patients were randomized to either a once daily dosing scheme, including a loading dose of 20-25 mg/kg, or a twice daily dosing scheme without a loading dose. Data was analyzed using a 2-compartment PK model using NONLIN. The pediatric patients under 1 year were split into 2 groups of 30 patients based on age, a group of patients aged $<6$ months (median age 8 weeks) and a group of children 6-12 months (median age 28 weeks). Children older than 1 year were included in a group also including adults (median age 34 years). Vd in patients $<1$ year was larger $(0.58$ and $0.50 \mathrm{l} / \mathrm{kg}$ for patients $<6$ months and 6-12 months, respectively) than older patients $(0.331 / \mathrm{kg})$. In addition, $\mathrm{Cl}$ was higher in younger patients 0.063 and $0.068 \mathrm{l} / \mathrm{kg} / \mathrm{h}$ vs. $0.051 \mathrm{l} / \mathrm{kg} / \mathrm{h}$ in older patients. Elimination $t^{1 / 2}$ was longest in children $<6$ months $(5.02 \mathrm{~h})$ and shortest in children $6-12$ months $(2.86 \mathrm{~h})$. Target-attainment, defined as Cmax $>20 \mathrm{mg} / \mathrm{l}$ and $\mathrm{Cmin}<5 \mathrm{mg} / \mathrm{l}$, was $100 \%$ in the group with once daily dosing and 79\% (Cmax target) and $44 \%$ (Cmin target) for twice daily dosing. Children required higher daily doses in $\mathrm{mg} / \mathrm{kg}$ to reach these targets: $21 \mathrm{mg} / \mathrm{kg} /$ day for 6-12 months, $18.6-20.5 \mathrm{mg} / \mathrm{kg} /$ day for $<6$ months and $13.8-15.5 \mathrm{mg} / \mathrm{kg} / \mathrm{day}$ for older patients.

The 2 other studies used a cohort of patients treated with amikacin, with Bressolle et al. including both children and adults in their 2-compartment model [64]. Patients received doses ranging from 70 to $1500 \mathrm{mg}$, however the dose in $\mathrm{mg} /$ $\mathrm{kg} /$ day the pediatric patients received is not reported. The only PK-data that was separately presented for the pediatric population were $\mathrm{Cmax}$ and $\mathrm{Cmin}$ values. Mean Cmax and Cmin values in the pediatric study population were 40.7 and $0.97 \mathrm{mg} / \mathrm{l}$, respectively. These values were validated in a test-population of 8 additional children, which showed lower Cmax of $16.0 \mathrm{mg} / \mathrm{l}$ and higher Cmin, $1.40 \mathrm{mg} / \mathrm{l}$. After Bayesian estimation for children, predicted concentrations for Cmax and Cmin were $16.2 \mathrm{mg} / \mathrm{l}$ and $1.45 \mathrm{mg} / \mathrm{l}$, respectively.

Sherwin et al. only included patients with burns in their study, with a median burned surface area of $43 \%$ [65]. Both studies by Bressolle and Sherwin used a wide pediatric age range from 6 months to 15 and 17 years, respectively, 
and both studies included patients with renal dysfunction $[64,65]$. Studied covariates included weight and height, and Sherwin et al. also tested age, gender, percentage of burned surface area and serum creatinine as covariates, but none improved the model significantly [65]. Population parameters for $\mathrm{Cl}$ and $\mathrm{Vd}$ were normalized for a typical $70 \mathrm{~kg}$ patient. Amikacin $\mathrm{Cl}$ was $5.98 \mathrm{l} / \mathrm{h} / 70 \mathrm{~kg}$ and $\mathrm{Vd}$ was $16.7 \mathrm{l} / 70 \mathrm{~kg}$ for the central compartment and $40.1 \mathrm{l} / 70 \mathrm{~kg}$ for the peripheral compartment. These values are higher than the $\mathrm{Cl}$ and $\mathrm{Vd}$ of the previously discussed study by Marik et al. [63], indicating altered PK in burn patients.

\subsubsection{Netilmicin}

Only 1 study on netilmicin PK in pediatric patients was available [66]. This study by Wagner et al. mainly included neonatal patients; only 9 of the total of 66 patients, with a mean age of 4.6 years were admitted to the pediatric ICU. Patients were treated with a once daily dose of $6 \mathrm{mg} / \mathrm{kg}$. The authors mentioned a reduced dose and prolonged dosing interval for patients with renal insufficiency, but no patients with renal dysfunction were included in the pediatric cohort. The only PK-data that are presented are Cmax and Cmin values for pediatric patients. Mean Cmax values were $33 \mathrm{mg} / \mathrm{l}$ (range $23-41 \mathrm{mg} / \mathrm{l}$ ) and Cmin values were $1.3 \mathrm{mg} / \mathrm{l}$ (range $0.2-3.2 \mathrm{mg} / \mathrm{l})$. The authors concluded that once daily dosing of netilmicin is sufficient to reach adequate targets.

\subsection{Other Antibiotics Agents with Eligible Studies in Our Search}

\subsubsection{Daptomycin}

2 case-reports and 1 pharmacometric model were available for daptomycin that included PK parameters [67-69]. Both patients in the case reports suffered from cardiac problems, a 13 year old boy with endocarditis [67] and a 8 year old girl with multi-organ failure (including renal insufficiency) awaiting heart transplantation [68]. Similar doses were used in both studies (6-8 $\mathrm{mg} / \mathrm{kg}$ every $24 \mathrm{~h}$ ). The dose interval was prolonged to $48 \mathrm{~h}$ for the patient with renal insufficiency [68].

Morris et al. only presented steady state $\mathrm{Cmax}$ and $\mathrm{Cmin}$ values, which were $68 \mathrm{mg} / \mathrm{l}$ and $14.6 \mathrm{mg} / \mathrm{l}$, respectively [68]. These values were within the desired target of Cmin below $20 \mathrm{mg} / \mathrm{l}$. Akins et al. provided Cmax and Cmin concentrations after a single dose and in steady state [67]. In addition, $\mathrm{Vd}, \mathrm{Cl}, t^{1 / 2}, k$ and AUC values were presented for both the first dose and in steady state. Cmax were higher and Cmin concentrations were lower than the values reported by Morris et al., both after the first dose as in steady state. Values in steady state for $\mathrm{Vd}$ and $\mathrm{Cl}$ were $0.089 \mathrm{l} / \mathrm{kg}$ and $0.0137 \mathrm{l} /$ $\mathrm{kg} / \mathrm{h}$, respectively. $t^{1 / 2}$ in steady state was $4.58 \mathrm{~h}$, with an AUC of $594 \mathrm{mg} / \mathrm{l} / \mathrm{h}$.

The pharmacometric model by Antachopoulos included data of 4 patients aged from 8 to 14 years old with mixed disease conditions in their one compartment model [69]. On the first day of treatment, 3 of the 4 patients met pediatric criteria for sepsis. The patients with sepsis had a significantly higher $\mathrm{Cl}$ (median $\mathrm{Cl} 0.0423 \mathrm{l} / \mathrm{kg} / \mathrm{h}$ ) compared to the patient without sepsis $(0.0151 \mathrm{l} / \mathrm{kg} / \mathrm{h})$. Vd was also higher in patients that met sepsis criteria $(0.261 / \mathrm{kg}$, compared to $0.161 / \mathrm{kg}$ for the non-sepsis patient). This resulted in a lower $\mathrm{AUC}_{0-\infty}$ and lower Cmax values of daptomycin in sepsis patients compared to non-sepsis patients (AUC ${ }_{0-\infty} 236.5 \mathrm{mg} / \mathrm{h} / \mathrm{l}$ vs. $663.9 \mathrm{mg} / \mathrm{h} / \mathrm{l}$ and Cmax $35.4 \mathrm{mg} / \mathrm{l} \mathrm{vs.}$ $59.8 \mathrm{mg} / \mathrm{l}$, respectively). PK parameters on the 5 th day were comparable with the first day, with a higher $\mathrm{Cl}$, larger $\mathrm{Vd}$, lower $\mathrm{AUC}_{0-24 \mathrm{~h}}$ and $\mathrm{Cmax}$ in the 2 patients meeting sepsis criteria.

\subsubsection{Ciprofloxacin}

Lipman et al. published the only study on ciprofloxacin in 20 patients between 3 months and 5 years with severe sepsis [70]. Patients received a daily dose of $20 \mathrm{mg} / \mathrm{kg} /$ day in 2 doses during 1-2 weeks of treatment. The authors used non-compartmental analysis to determine PK-parameters in 2 age groups, 3 months-1 year and 1-5 years of age. No significant differences in PK-parameters between these 2 age groups were seen. When using a target of $\mathrm{Cmax} / \mathrm{MIC}=8$, the authors concluded that a dose of $20 \mathrm{mg} / \mathrm{kg} /$ day is sufficient to cover pathogens with an MIC up to $0.8 \mathrm{mg} / 1$. To reach the target of AUC/MIC of 100-150 in PICU patients with a normal renal function infected by more resistant microorganisms the authors advise a daily dose of $30 \mathrm{mg} / \mathrm{kg} / \mathrm{day}$ in 3 doses.

\section{Discussion}

Although antibiotic use in critically ill children is one of the pillars of intensive care treatment, from our review we can conclude that current knowledge on the PK and target attainment of these drugs in critically ill children is relatively scarce. Nevertheless, an important finding is that target attainment is often suboptimal in this patient population using standard doses of different classes of antibiotics [19, 21, 24-26, 28, 29, 41, 43, 45, 46, 50, 55, 56, 59, 62, 63, 69].

Not unexpectedly, a large number of manuscripts focus on agents where TDM is generally applied during routine care, such as vancomycin and gentamicin, as data are relatively readily available from medical records. In contrast, to the best of our knowledge, other frequently used agents (like ceftriaxone, ceftazidime, penicillin, flucloxacillin, 
metronidazole) completely lack PK data in the pediatric ICU population [71, 72]. In addition, only the minority of included articles (22/50) provide dosing guidance for clinicians, even though in most publications (38/50) the necessary data on $\mathrm{Vd}$ and $\mathrm{Cl}$ was available to simulate optimal dosing regimens.

When comparing the findings on these different antibiotics in critically ill children to data in critically ill adults and/ or healthy children, it is apparent that $\mathrm{PK}$ alterations occur in this patient population. For example, $\mathrm{Cl}$ values of amoxicillin are almost double in critically ill children $(0.24 \mathrm{l} / \mathrm{kg} / \mathrm{h})$ compared to critically ill adults $(0.13 \mathrm{l} / \mathrm{kg} / \mathrm{h})$ but with a similar Vd (0.37-0.47 1/kg in children vs. $0.371 / \mathrm{kg}$ in adults) [73]. For piperacillin, two studies in critically ill children show slightly higher $\mathrm{Cl}$ values $[24,25]$ than in critically ill adults with hyperfiltration [74], but this is not supported by two other publications [23, 26]. Cefotaxime $\mathrm{Cl}$ was almost $50 \%$ higher in critically ill children [28] while mean $\mathrm{Vd}$ was markedly smaller than values reported in non-critically ill children [75], resulting in a shorter $t^{1 / 2}$ and higher recommended doses to reach common PD targets. Median values of vancomycin $\mathrm{Cl}$ and $\mathrm{Vd}$ in the studies in this review exceed values of non-critically ill children, pediatric cancer patients $[76,77]$ and critically ill adults $[78,79]$.

These altered PK parameters are most likely the result of a combination of disease-related alterations and age-related changes in PK [5]. Disease-related changes may impact PK by a multitude of pathophysiological mechanisms. Firstly, fluid resuscitation is a common therapy for hemodynamically unstable critically ill patients, that may result in an increase in total body water, larger $\mathrm{Vd}$ and therefore dilution of hydrophilic compounds. Systemic inflammatory response syndrome (SIRS), caused by inflammatory cytokines, induces capillary leak and the shift of intravascular fluid to the extravascular space [80]. This 'third-spacing' of fluid may reduce drug concentrations, not only in plasma but also at the site of infection. Furthermore, hypoalbuminaemia is common among critically ill children, causing a relatively large fraction of unbound drug that is available to distribute to peripheral tissues, which mostly influences highly protein bound drugs ( $>80 \%$ protein binding) [42, 81, 82]. These alterations in Vd mainly affect concentration-dependent antibiotics, such as aminoglycosides which require a high Cmax value for optimized bacterial killing [83, 84]. Also, inflammation and critical illness appear to downregulate drug metabolism, such as seen with CYP3A-mediated midazolam metabolism in critically ill children [85] and CYP2C9-mediated warfarin metabolism in critically ill adults [86].

In addition to changes in $\mathrm{Vd}$, protein binding and drug metabolism, renal $\mathrm{Cl}$ of drugs can be altered during critical illness. AKI in critically ill children is primarily caused by reduced renal blood flow (e.g. due to volume depletion or decreased arterial blood pressure) and glomerular or tubular damage due to cytokine release, disseminated intravascular coagulation or nephrotoxic agents $[87,88]$. AKI is common with a prevalence of around $35 \%$ in critically ill children, causing a reduced renal $\mathrm{Cl}$ and potential supratherapeutic or toxic concentrations of renally excreted drugs [89]. While a general picture of reduced target-attainment in critically ill children may arise from our review, several studies do report supratherapeutic plasma concentrations for some of the toxic antibiotics like aminoglycosides or glycopeptides in a small proportion of patients $[41,43,53,63]$.

This counter-intuitive finding of reduced exposure in critically ill children, may be explained by a high incidence of ARC. Contrary to AKI, ARC has been identified in up to $67 \%$ of both critically ill adults [8] and children [10]. This is in line with several studies in this review showing extremely high drug $\mathrm{Cl}$ and/or eGFR in this patient population [21, 26, 50, 52]. A recent review by Dhont et al. on ARC in children shows that time-dependent antibiotics, like $\beta$-lactam antibiotics, which require drug concentrations above an MIC-threshold for a prolonged period of time, could be at the highest risk for non-target attainment due to this phenomenon [9]. However, a correlation between ARC and subtherapeutic drug concentrations or clinical outcome could not be made due to multiple confounding factors that also contribute to subtherapeutic drug concentrations and adverse outcome of critically ill children.

Furthermore, age-related changes in the processes involved in disposition, metabolism and excretion of drugs may impact both $\mathrm{Vd}$ and $\mathrm{Cl}$. Changes in $\mathrm{Vd}$ in neonates and young infants may results from a different body composition, with a higher proportion of body water compared to adults [11], mainly influencing hydrophilic compounds like the majority of antibiotic agents. Developmental changes affecting drug $\mathrm{Cl}$ include a lower (absolute) GFR and tubular excretion in neonates and children younger than 2 years of age [11]. Interestingly, when $\mathrm{Cl}$ values are weight-corrected the renal clearance reaches adult levels relatively quickly, within the first month of life [90]. In addition, weight-corrected GFR is almost $70 \%$ higher in 2-5 year old children than in adults while renal blood flow and tubular secretion stay relatively stable [91]. This relation between age and GFR might be contributed to the relatively larger kidney size in children compared to adults [90]. Since the majority of studies in this review had a median age of included patients between 1 and 5 years of age, this could be a possible explanation of the higher weight-corrected $\mathrm{Cl}$ compared to adult populations.

Lastly, although PD targets for antibiotic agents are partially drug-specific, determined by a drugs' kill-characteristic, and partially defined by pathogenic susceptibility, defined as the MIC value, only the former is accounted for in dosing recommendations. While MIC-based dosing would seem to provide an improvement in the attainment of $\mathrm{PD}$ 
targets, there are numerous drawbacks to using MIC values in dosing guidelines as outlined by Mouton et al. [92]. In summary, the in vitro MIC assay is insufficiently accurate and reproducible to adequately represent conditions in vivo and therefore cannot be used as an exact concentration to strife for during treatment. Doing so possibly leads to an underestimation of the antibiotic effect in vivo [93, 94] or missed treatment options [95]. Secondly, the MIC that is used in the desired PD targets is regarded as static value but should be seen more as a distribution of MICs within a bacterial strain [92]. In addition, PD might also be affected by alterations in PK [96]. In their semi-mechanistic PK/PD model Nielsen et al. have simulated the effects of a wide range of dosing regimens of six antibiotics from in vitro time-kill curve experiments. The authors state that when the PK-profile of benzylpenicillin, a hydrophilic $\beta$-lactam antibiotic with a short $t^{1} / 2$, was used for other antibiotics, fT > MIC was still the best predictor of effect, even for antibiotics that are normally regarded as concentrationdependent or exposure-dependent. Lastly, the susceptibility of pathogens is heavily region-bound, making it difficult to extrapolate dosing advices between regions with different resistance patterns.

A logic next step seems to incorporate both age- and disease related co-variates in dosing guidelines using modelling and simulation. Most of the PopPK modelling studies in this review have incorporated (allometrically scaled) age and/or weight covariates in their final models $[21,25,26,28,51$, $52,55,57,61,65]$. However, models incorporating (bio) markers of organ failure (e.g. eGFR, serum creatinin, albumin, C-reactive protein, transaminases) as covariate were limited [21, 25, 26, 28, 51, 52, 55, 57]. Of the 48 studies, only 5 PK models have incorporated eGFR in their estimations for drug $\mathrm{Cl}[21,26,51,55,57]$ and only 3 additional studies found a significant relation between serum creatinine and drug concentration [29, 45,60]. Other studies have either not investigated this relationship or found the addition of creatinine clearance to be non-significant. This might reflect that serum creatinine is a suboptimal marker for GFR in this population and/or the impact of other factors than GFR on the variability in drug clearance. The inability to accurately estimate drug clearance using biomarkers is one of the fundamental challenges regarding optimizing target attainment in this patient population.

In order to overcome suboptimal target attainment of antibiotics in critically ill children clinicians have several options. Firstly, increasing the dose or dose frequency of an antibiotic could provide an easy solution to increase exposure and therefore increase target attainment. However, a linear dose increase might introduce increased toxicity and will not account for the extremely large within and between subject variability in PK seen in critically ill patients caused by pathophysiological changes, heterogeneity of underlying diseases and extracorporeal circuits seen in PICU patients. Secondly, continuous or extended infusion could be used for time-dependent antibiotics, like $\beta$-lactam antibiotics, in order to optimize dosing regimens to the established PK-PD relationship. Continuous or extended infusion has been proposed in almost all $\beta$-lactam modelling studies found in this review $[21,23-26,28,32,35,61]$ and is recommended in a recent guideline from the French Society of Anaesthesia and Intensive Care Medicine (SFAR) [97]. Additionally, clinicians can be supported by PK-PD software using a combination of PopPK models, Bayesian forecasting and TDM, to ensure optimal target attainment in special populations or individual patients. In the previously mentioned SFAR guideline the use of TDM is also recommend, including an overview of suggested PD targets for several $\beta$-lactam antibiotics [97]. However, although several software packages are available [5], successful clinical implementation requires close collaboration between clinicians and pharmacists. Additionally, it is still unknown whether optimizing target attainment of antibiotics will result in a clinical benefit in terms of survival or duration of ICU-stay. Although several meta-analyses and large clinical studies show contradicting evidence in adults [98-103], 1 smaller study showed a low mortality of only $4.2 \%$ in a selective pediatric sepsis cohort when TDM and non-standard dosing was applied, even after initial subtherapeutic antibiotic concentrations [3]. Ideally, large clinical trials aiming to identify whether this increased target attainment of antibiotics leads to a reduced morbidity and/or mortality should be conducted in both critically ill adult and pediatric patients.

\section{Conclusion}

This systematic review shows that the PK of most antibiotics is significantly altered during critical illness in children. For most drugs both $\mathrm{Vd}$ and $\mathrm{Cl}$ are increased, putting this population at increased risk for suboptimal target attainment. A second main finding in this review is the lack of knowledge of PK in critically ill children of several, frequently used antibiotic agents such as ceftriaxone, ceftazidime, penicillin, flucloxacillin and metronidazole. Finally, the majority of articles do not provide any dosing guidance for PICU patients, even if the necessary PK-parameters to simulate dosing regimens are presented in the paper.

Adequate antibiotic dosing of critically ill children is challenging, due to a wide range pathophysiological changes, developmental differences between different age groups and great within and between subject variability in PK. This challenging landscape requires close collaboration between clinicians, pharmacists and clinical pharmacologists, as expertise of all these parties is required for an accurate assessment of this patient population. This literature 
overview hopes to inspire both researchers and clinicians in this field to close these gaps, not only by presenting pharmacokinetic data, but also by providing guidance for implementation in the clinic, as this information is vital to optimize antibiotic treatment in this vulnerable population.

\section{Compliance with Ethical Standards}

Funding Financial support from institutions Radboudumc, Nijmegen, The Netherlands.

Conflict of interest Stan J. F. Hartman, Roger J. Brüggemann, Lynn Orriëns, Nada Dia, Michiel F. Schreuder and Saskia N. de Wildt declare that they have no conflict of interest.

Open Access This article is distributed under the terms of the Creative Commons Attribution-NonCommercial 4.0 International License (http://creativecommons.org/licenses/by-nc/4.0/), which permits any noncommercial use, distribution, and reproduction in any medium, provided you give appropriate credit to the original author(s) and the source, provide a link to the Creative Commons license, and indicate if changes were made.

\section{References}

1. van Houten MA, Luinge K, Laseur M, Kimpen JL. Antibiotic utilisation for hospitalised paediatric patients. Int J Antimicrob Agents. 1998;10(2):161-4. https://doi.org/10.1016/S0924 -8579(98)00022-3.

2. De Waele JJ, Lipman J, Akova M, Bassetti M, Dimopoulos G, Kaukonen M, et al. Risk factors for target non-attainment during empirical treatment with beta-lactam antibiotics in critically ill patients. Intensive Care Med. 2014;40(9):1340-51. https://doi. org/10.1007/s00134-014-3403-8.

3. Cies JJ, Moore WS 2nd, Enache A, Chopra A. Beta-lactam therapeutic drug management in the PICU. Crit Care Med. 2017. https ://doi.org/10.1097/ccm.0000000000002817.

4. Tsai D, Lipman J, Roberts JA. Pharmacokinetic/pharmacodynamic considerations for the optimization of antimicrobial delivery in the critically ill. Curr Opin Crit Care. 2015;21(5):412-20. https://doi.org/10.1097/MCC.0000000000000229.

5. Roberts JA, Abdul-Aziz MH, Lipman J, Mouton JW, Vinks AA, Felton TW, et al. Individualised antibiotic dosing for patients who are critically ill: challenges and potential solutions. Lancet Infect Dis. 2014;14(6):498-509. https://doi.org/10.1016/S1473 -3099(14)70036-2.

6. Blot SI, Pea F, Lipman J. The effect of pathophysiology on pharmacokinetics in the critically ill patient-concepts appraised by the example of antimicrobial agents. Adv Drug Deliv Rev. 2014;77:3-11. https://doi.org/10.1016/j.addr.2014.07.006.

7. Udy AA, Roberts JA, Boots RJ, Paterson DL, Lipman J. Augmented renal clearance: implications for antibacterial dosing in the critically ill. Clin Pharmacokinet. 2010;49(1):1-16. https:// doi.org/10.2165/11318140-000000000-00000.

8. Udy AA, Baptista JP, Lim NL, Joynt GM, Jarrett P, Wockner $\mathrm{L}$, et al. Augmented renal clearance in the ICU: results of a multicenter observational study of renal function in critically ill patients with normal plasma creatinine concentrations*. Crit Care Med. 2014;42(3):520-7. https://doi.org/10.1097/ CCM.0000000000000029.
9. Dhont E, Van Der Heggen T, De Jaeger A, Vande Walle J, De Paepe P, De Cock PA. Augmented renal clearance in pediatric intensive care: are we undertreating our sickest patients? Pediatr Nephrol. 2018. https://doi.org/10.1007/s00467-018-4120-2.

10. Van Der Heggen T, Dhont E, Peperstraete H, Delanghe JR, Vande Walle J, De Paepe P, et al. Augmented renal clearance: a common condition in critically ill children. Pediatr Nephrol. 2019. https:// doi.org/10.1007/s00467-019-04205-x.

11. Kearns GL, Abdel-Rahman SM, Alander SW, Blowey DL, Leeder JS, Kauffman RE. Developmental pharmacology_drug disposition, action, and therapy in infants and children. N Engl J Med. 2003;349(12):1157-67. https://doi.org/10.1056/NEJMr a035092.

12. Tängdén T, Ramos Martin V, Felton TW, Nielsen EI, Marchand $\mathrm{S}$, Bruggemann RJ, et al. The role of infection models and PK/ PD modelling for optimising care of critically ill patients with severe infections. Intensive Care Med. 2017;43(7):1021-32. https://doi.org/10.1007/s00134-017-4780-6.

13. De Waele JJ, Carrette S, Carlier M, Stove V, Boelens J, Claeys $\mathrm{G}$, et al. Therapeutic drug monitoring-based dose optimisation of piperacillin and meropenem: a randomised controlled trial. Intensive Care Med. 2014;40(3):380-7. https://doi. org/10.1007/s00134-013-3187-2.

14. Economou CJP, Wong G, McWhinney B, Ungerer JPJ, Lipman J, Roberts JA. Impact of beta-lactam antibiotic therapeutic drug monitoring on dose adjustments in critically ill patients undergoing continuous renal replacement therapy. Int J Antimicrob Agents. 2017;49(5):589-94. https://doi.org/10.1016/j. ijantimicag.2017.01.009.

15. Jager NG, van Hest RM, Lipman J, Taccone FS, Roberts JA. Therapeutic drug monitoring of anti-infective agents in critically ill patients. Expert Rev Clin Pharmacol. 2016;9(7):96179. https://doi.org/10.1586/17512433.2016.1172209.

16. Wong G, Briscoe S, McWhinney B, Ally M, Ungerer J, Lipman J, et al. Therapeutic drug monitoring of beta-lactam antibiotics in the critically ill: direct measurement of unbound drug concentrations to achieve appropriate drug exposures. J Antimicrob Chemother. 2018;73(11):3087-94. https://doi. org/10.1093/jac/dky314.

17. MeSH Database. Anti-bacterial Agents [Pharmacological Action] https://www.ncbi.nlm.nih.gov/mesh/82000900. Accessed 01 Apr 2017.

18. Reed MD, Yamashita TS, Myers CM, Blumer JL. The pharmacokinetics of teicoplanin in infants and children. J Antimicrob Chemother. 1997;39(6):789-96. https://doi.org/10.1093/ jac/39.6.789.

19. De Cock PA, Mulla H, Desmet S, De Somer F, McWhinney $\mathrm{BC}$, Ungerer JP, et al. Population pharmacokinetics of cefazolin before, during and after cardiopulmonary bypass to optimize dosing regimens for children undergoing cardiac surgery. J Antimicrob Chemother. 2017;72(3):791-800. https://doi. org/10.1093/jac/dkw496.

20. Cies JJ, Moore WS 2nd, Parker J, Stevens R, Al-Qaqaa Y, Enache A, et al. Pharmacokinetics of cefazolin delivery via the cardiopulmonary bypass circuit priming solution in infants and children. J Antimicrob Chemother. 2019. https://doi. org/10.1093/jac/dky574.

21. De Cock PA, Standing JF, Barker CI, de Jaeger A, Dhont E, Carlier M, et al. Augmented renal clearance implies a need for increased amoxicillin-clavulanic acid dosing in critically ill children. Antimicrob Agents Chemother. 2015;59(11):702735. https://doi.org/10.1128/AAC.01368-15.

22. Jones AE, Barnes ND, Tasker TC, Horton R. Pharmacokinetics of intravenous amoxycillin and potassium clavulanate in seriously ill children. J Antimicrob Chemother. 1990;25(2):26974. https://doi.org/10.1093/jac/25.2.269. 
23. Nichols K, Chung EK, Knoderer CA, Buenger LE, Healy DP, Dees J, et al. Population pharmacokinetics and pharmacodynamics of extended-infusion piperacillin and tazobactam in critically ill children. Antimicrob Agents Chemother. 2015;60(1):522-31. https://doi.org/10.1128/AAC.02089-15.

24. Cies JJ, Shankar V, Schlichting C, Kuti JL. Population pharmacokinetics of piperacillin/tazobactam in critically ill young children. Pediatr Infect Dis J. 2014;33(2):168-73. https://doi. org/10.1097/INF.0b013e3182a743c7.

25. De Cock PA, van Dijkman SC, de Jaeger A, Willems J, Carlier M, Verstraete AG, et al. Dose optimization of piperacillin/tazobactam in critically ill children. J Antimicrob Chemother. 2017. https://doi.org/10.1093/jac/dkx093.

26. Béranger A, Benaboud S, Urien S, Moulin F, Bille E, Lesage $\mathrm{F}$, et al. Piperacillin population pharmacokinetics and dosing regimen optimization in critically ill children with normal and augmented renal clearance. Clin Pharmacokinet. 2018. https:// doi.org/10.1007/s40262-018-0682-1.

27. Von Hattingberg HM, Marget W, Belohradsky BH, Roos R. Pharmacokinetics of cefotaxime in neonates and children: clinical aspects. J Antimicrob Chemother. 1980;6(SUPPL.A):113-8. https://doi.org/10.1093/jac/6.suppl_a.113.

28. Béranger A, Oualha M, Urien S, Genuini M, Renolleau S, Aboura R, et al. Population pharmacokinetic model to optimize cefotaxime dosing regimen in critically ill children. Clin Pharmacokinet. 2018;57(7):867-75. https://doi.org/10.1007/s4026 2-017-0602-9.

29. Hartman SJF, Boeddha NP, Ekinci E, Koch BCP, Donders R, Hazelzet JA, et al. Target attainment of cefotaxime in critically ill children with meningococcal septic shock as a model for cefotaxime dosing in severe pediatric sepsis. Eur J Clin Microbiol Infect Dis. 2019. https://doi.org/10.1007/s10096-019-03535-w.

30. Olguin HJ, Asseff IL, Vieyra AC, Perez AG, Saldana NG, Quesada AC, et al. Effect of severity disease on the pharmacokinetics of cefuroxime in children with multiple organ system failure. Biol Pharm Bull. 2008;31(2):316-20. https://doi.org/10.1248/ bpb.31.316.

31. Haessler D, Reverdy ME, Neidecker J, Brule P, Ninet J, Lehot JJ. Antibiotic prophylaxis with cefazolin and gentamicin in cardiac surgery for children less than ten kilograms. J Cardiothorac Vasc Anesth. 2003;17(2):221-5. https://doi.org/10.1053/jcan.2003.51.

32. Cies JJ, Moore WS 2nd, Enache A, Chopra A. Ceftaroline for suspected or confirmed invasive methicillin-resistant staphylococcus aureus: a pharmacokinetic case series. Pediatr Crit Care Med. 2018. https://doi.org/10.1097/pcc.0000000000001497.

33. Forest Pharmaceutical IT T, Italy. Ceftaroline [package insert]. 2015.

34. Cies JJ, Moore WS, Calaman S, Brown M, Narayan P, Parker $\mathrm{J}$, et al. Pharmacokinetics of continuous-infusion meropenem for the treatment of Serratia marcescens ventriculitis in a pediatric patient. Pharmacotherapy. 2015;35(4):E32-6. https://doi. org/10.1002/phar.1567.

35. Cies JJ, Moore WS 2nd, Enache A, Chopra A. Population pharmacokinetics and pharmacodynamic target attainment of meropenem in critically ill young children. J Pediatr Pharmacol Ther. 2017;22(4):276-85. https://doi.org/10.5863/1551-6776-22.4.276.

36. Du X, Li C, Kuti JL, Nightingale CH, Nicolau DP. Population pharmacokinetics and pharmacodynamics of meropenem in pediatric patients. J Clin Pharmacol. 2006;46(1):69-75. https://doi. org/10.1177/0091270005283283.

37. Blumer JL, Reed MD, Kearns GL, Jacobs RF, Gooch WM 3rd, Yogev R, et al. Sequential, single-dose pharmacokinetic evaluation of meropenem in hospitalized infants and children. Antimicrob Agents Chemother. 1995;39(8):1721-5. https://doi. org/10.1128/aac.39.8.1721.
38. Giannoni E, Moreillon P, Cotting J, Moessinger A, Bille J, Decosterd L, et al. Prospective determination of plasma imipenem concentrations in critically ill children. Antimicrob Agents Chemother. 2006;50(7):2563-8. https://doi.org/10.1128/ aac.01149-05.

39. Cies JJ, LaCoursiere RJ, Moore WS 2nd, Chopra A. Therapeutic drug monitoring of prolonged infusion aztreonam for multi-drug resistant Pseudomonas aeruginosa: a case report. J Pediatr Pharmacol Ther. 2017;22(6):467-70. https://doi. org/10.5863/1551-6776-22.6.467.

40. Bristol-Myers-Squibb. Aztreonam (Azactam) [package insert]. Revised Sep 2018.

41. Bonazza S, Bresee LC, Kraft T, Ross BC, Dersch-Mills D. Frequency of and risk factors for acute kidney injury associated with vancomycin use in the pediatric intensive care unit. J Pediatr Pharmacol Ther. 2016;21(6):486-93. https://doi. org/10.5863/1551-6776-21.6.486.

42. De Cock PA, Desmet S, De Jaeger A, Biarent D, Dhont E, Herck I, et al. Impact of vancomycin protein binding on target attainment in critically ill children: back to the drawing board? J Antimicrob Chemother. 2016. https://doi.org/10.1093/jac/dkw495.

43. Seixas GT, Araujo OR, Silva DC, Arduini RG, Petrilli AS. Vancomycin therapeutic targets and nephrotoxicity in critically ill children with cancer. J Pediatr Hematol Oncol. 2016;38(2):e5662. https://doi.org/10.1097/MPH.0000000000000470.

44. Cies JJ, Shankar V. Nephrotoxicity in patients with vancomycin trough concentrations of $15-20 \mathrm{mug} / \mathrm{ml}$ in a pediatric intensive care unit. Pharmacotherapy. 2013;33(4):392-400. https://doi. org/10.1002/phar.1227.

45. Silva DC, Seixas GT, Araujo OR, Arduini RG, Carlesse FA, Petrilli AS. Vancomycin serum concentrations in pediatric oncologic/hematologic intensive care patients. Braz J Infect Dis. 2012;16(4):361-5. https://doi.org/10.1016/j.bjid.2012.06.011.

46. Giachetto GA, Telechea HM, Speranza N, Oyarzun M, Nanni L, Menchaca A. Vancomycin pharmacokinetic-pharmacodynamic parameters to optimize dosage administration in critically ill children. Pediatr Crit Care Med. 2011;12(6):e250-4. https://doi. org/10.1097/PCC.0b013e3181fe4047.

47. Glover ML, Cole E, Wolfsdorf J. Vancomycin dosage requirements among pediatric intensive care unit patients with normal renal function. J Crit Care. 2000;15(1):1-4. https://doi. org/10.1053/jcrc.2000.0150001.

48. Gous AG, Dance MD, Lipman J, Luyt DK, Mathivha R, Scribante J. Changes in vancomycin pharmacokinetics in critically ill infants. Anaesth Intensive Care. 1995;23(6):678-82. https://doi. org/10.1177/0310057X9502300603.

49. Totapally BR, Machado J, Lee H, Paredes A, Raszynski A. Acute kidney injury during vancomycin therapy in critically ill children. Pharmacotherapy. 2013;33(6):598-602. https://doi.org/10.1002/ phar.1259.

50. Goboova M, Kuzelova M, Kissova V, Bodakova D, Martisova E. An adjustment of vancomycin dosing regimen for a young patient with augmented renal clearance: a case report. Acta Fac Pharm Univ Comen. 2015;62(2):1-4. https://doi.org/10.1515/ afpuc-2015-0025.

51. Zane NR, Reedy MD, Gastonguay MR, Himebauch AS, Ramsey EZ, Topjian AA, et al. A population pharmacokinetic analysis to study the effect of therapeutic hypothermia on vancomycin disposition in children resuscitated from cardiac arrest. Pediatr Crit Care Med. 2017;18(7):e290-7. https://doi.org/10.1097/ PCC.0000000000001198.

52. Avedissian SN, Bradley E, Zhang D, Bradley JS, Nazer LH, Tran $\mathrm{TM}$, et al. Augmented renal clearance using population-based pharmacokinetic modeling in critically ill pediatric patients. Pediatr Crit Care Med. 2017. https://doi.org/10.1097/pcc.00000 00000001228. 
53. Thomas CA, Picone A, Menon S, Willis BC. Empiric vancomycin dosing in pediatric patients with congenital heart disease and the impact of cardiopulmonary bypass on trough concentrations. Pharmacotherapy. 2017. https://doi.org/10.1002/phar.2019.

54. Holsen MR, Meaney CJ, Hassinger AB, Fusco NM. Increased risk of acute kidney injury in critically ill children treated with vancomycin and piperacillin/tazobactam. Pediatr Crit Care Med. 2017;1:4. https://doi.org/10.1097/pcc.0000000000001335.

55. Genuini M, Oualha M, Bouazza N, Moulin F, Treluyer JM, Lesage $\mathrm{F}$, et al. Achievement of therapeutic vancomycin exposure with continuous infusion in critically ill children. Pediatr Crit Care Med. 2018. https://doi.org/10.1097/pcc.000000000000147 4.

56. Fitzgerald JC, Zane NR, Himebauch AS, Reedy MD, Downes KJ, Topjian AA, et al. Vancomycin prescribing and therapeutic drug monitoring in children with and without acute kidney injury after cardiac arrest. Paediatr Drugs. 2019. https://doi.org/10.1007/ s40272-019-00328-8.

57. Moffett BS, Resendiz K, Morris J, Akcan-Arikan A, Checchia PA. Population pharmacokinetics of vancomycin in the pediatric cardiac surgical population. J Pediatr Pharmacol Ther. 2019;24(2):107-16. https://doi.org/10.5863/1551-6776-24.2.107.

58. Lukas JC, Karikas G, Gazouli M, Kalabalikis P, Hatzis T, Macheras P. Pharmacokinetics of teicoplanin in an ICU population of children and infants. Pharm Res. 2004;21(11):2064-71. https:// doi.org/10.1023/B:PHAM.0000048198.56873.d8.

59. Sanchez A, Lopez-Herce J, Cueto E, Carrillo A, Moral R. Teicoplanin pharmacokinetics in critically ill paediatric patients. J Antimicrob Chemother. 1999;44(3):407-9. https://doi. org/10.1093/jac/44.3.407.

60. Zakova M, Pong S, Trope A, Atenafu EG, Papaioannou V, Bitnun $\mathrm{SA}$, et al. Dose derivation of once-daily dosing guidelines for gentamicin in critically ill pediatric patients. Ther Drug Monit. 2014;36(3):288-94. https://doi.org/10.1097/FTD.0000000000 000016.

61. Lopez SA, Mulla H, Durward A, Tibby SM. Extended-interval gentamicin: population pharmacokinetics in pediatric critical illness. Pediatr Crit Care Med. 2010;11(2):267-74. https://doi. org/10.1097/PCC.0b013e3181b80693.

62. Kraus DM, Dusik CM, Rodvold KA, Campbell MM, Kecskes SA. Bayesian forecasting of gentamicin pharmacokinetics in pediatric intensive-care unit patients. Pediatr Infect Dis J. 1993;12(9):713-8. https://doi.org/10.1097/00006454-19930 9000-00002.

63. Marik PE, Havlik I, Monteagudo FS, Lipman J. The pharmacokinetic of amikacin in critically ill adult and paediatric patients: comparison of once- versus twice-daily dosing regimens. J Antimicrob Chemother. 1991;27 Suppl C:81-9. https://doi. org/10.1093/jac/27.suppl_c.81.

64. Bressolle F, Gouby A, Martinez JM, Joubert P, Saissi G, Guillaud $\mathrm{R}$, et al. Population pharmacokinetics of amikacin in critically ill patients. Antimicrob Agents Chemother. 1996;40(7):1682-9. https://doi.org/10.1128/AAC.40.7.1682.

65. Sherwin CM, Wead S, Stockmann C, Healy D, Spigarelli MG, Neely A, et al. Amikacin population pharmacokinetics among paediatric burn patients. Burns. 2014;40(2):311-8. https://doi. org/10.1016/j.burns.2013.06.015.

66. Wagner BP, Pfenninger J. Once daily dosing of netilmicin in neonatal and pediatric intensive care. Intensive Care Med. 1994;20(5):365-7. https://doi.org/10.1007/BF01720910.

67. Akins RL, Haase MR, Levy EN. Pharmacokinetics of daptomycin in a critically ill adolescent with vancomycin-resistant enterococcal endocarditis. Pharmacotherapy. 2006;26(5):694-8. https://doi.org/10.1592/phco.26.5.694.

68. Morris S, Gould K, Ferguson LP. The use of daptomycin to treat methicillin-resistant Staphylococcus epidermidis bacteremia in a critically ill child with renal failure. J Pediatr Pharmacol Ther. 2017;22(4):300-3. https://doi.org/10.5863/1551-6776-22.4.300.

69. Antachopoulos C, Ilia S, Kadiltzoglou P, Baira E, Dokoumetzidis A, Gikas E, et al. Pharmacokinetics of daptomycin in critically ill pediatric patients. Antimicrob Agents Chemother. 2018;62:6. https://doi.org/10.1128/aac.02462-17.

70. Lipman J, Gous AG, Mathivha LR, Tshukutsoane S, Scribante $\mathrm{J}$, Hon H, et al. Ciprofloxacin pharmacokinetic profiles in paediatric sepsis: how much ciprofloxacin is enough? Intensive Care Med. 2002;28(4):493-500. https://doi.org/10.1007/s0013 4-002-1212-y.

71. Malacarne P, Rossi C, Bertolini G, GiVi TIG. Antibiotic usage in intensive care units: a pharmaco-epidemiological multicentre study. J Antimicrob Chemother. 2004;54(1):221-4. https://doi. org/10.1093/jac/dkh299.

72. Abbas Q, Ul Haq A, Kumar R, Ali SA, Hussain K, Shakoor S. Evaluation of antibiotic use in Pediatric Intensive Care Unit of a developing country. Indian J Crit Care Med. 2016;20(5):291-4. https://doi.org/10.4103/0972-5229.182197.

73. Carlier M, Stove V, Roberts JA, Van de Velde E, De Waele JJ, Verstraete AG. Quantification of seven beta-lactam antibiotics and two beta-lactamase inhibitors in human plasma using a validated UPLC-MS/MS method. Int J Antimicrob Agents. 2012;40(5):416-22. https://doi.org/10.1016/j.ijantimica g.2012.06.022.

74. Roberts JA, Kirkpatrick CM, Roberts MS, Dalley AJ, Lipman J. First-dose and steady-state population pharmacokinetics and pharmacodynamics of piperacillin by continuous or intermittent dosing in critically ill patients with sepsis. Int $\mathbf{J}$ Antimicrob Agents. 2010;35(2):156-63. https://doi.org/10.1016/j.ijantimica g.2009.10.008

75. Kafetzis DA, Brater DC, Kanarios J, Sinaniotis CA, Papadatos CJ. Clinical pharmacology of cefotaxime in pediatric patients. Antimicrob Agents Chemother. 1981;20(4):487-90. https://doi. org/10.1128/aac.20.4.487.

76. Krivoy N, Peleg S, Postovsky S, Ben Arush MW. Pharmacokinetic analysis of vancomycin in steady state in pediatric cancer patients. Pediatr Hematol Oncol. 1998;15(4):333-8. https://doi. org/10.3109/08880019809014017.

77. Chang D. Influence of malignancy on the pharmacokinetics of vancomycin in infants and children. Pediatr Infect Dis J. 1995;14(8):667-73.

78. Escobar L, Andresen M, Downey P, Gai MN, Regueira T, Borquez T, et al. Population pharmacokinetics and dose simulation of vancomycin in critically ill patients during high-volume haemofiltration. Int J Antimicrob Agents. 2014;44(2):163-7. https://doi.org/10.1016/j.ijantimicag.2014.03.009.

79. Llopis-Salvia P, Jimenez-Torres NV. Population pharmacokinetic parameters of vancomycin in critically ill patients. $\mathrm{J}$ Clin Pharm Ther. 2006;31(5):447-54. https://doi.org/10.111 1/j.1365-2710.2006.00762.x.

80. Teelucksingh S, Padfield PL, Edwards CR. Systemic capillary leak syndrome. Q J Med. 1990;75(277):515-24. https://doi. org/10.1093/oxfordjournals.qjmed.a068460.

81. Wong G, Briscoe S, Adnan S, McWhinney B, Ungerer J, Lipman $\mathrm{J}$, et al. Protein binding of beta-lactam antibiotics in critically ill patients: can we successfully predict unbound concentrations? Antimicrob Agents Chemother. 2013;57(12):6165-70. https:// doi.org/10.1128/AAC.00951-13.

82. Roberts JA, Stove V, De Waele JJ, Sipinkoski B, McWhinney $\mathrm{B}$, Ungerer JP, et al. Variability in protein binding of teicoplanin and achievement of therapeutic drug monitoring targets in critically ill patients: lessons from the DALI study. Int J Antimicrob Agents. 2014;43(5):423-30. https://doi.org/10.1016/j.ijantimica g.2014.01.023. 
83. Mouton JW, den Hollander JG. Killing of Pseudomonas aeruginosa during continuous and intermittent infusion of ceftazidime in an in vitro pharmacokinetic model. Antimicrob Agents Chemother. 1994;38(5):931-6. https://doi.org/10.1128/aac.38.5.931.

84. Craig WA. Pharmacokinetic/pharmacodynamic parameters: rationale for antibacterial dosing of mice and men. Clin Infect Dis. 1998;26(1):1-10. https://doi.org/10.1086/516284 quiz 1-2.

85. Vet NJ, Brussee JM, de Hoog M, Mooij MG, Verlaat CW, Jerchel IS, et al. Inflammation and organ failure severely affect midazolam clearance in critically ill children. Am J Respir Crit Care Med. 2016;194(1):58-66. https://doi.org/10.1164/rccm.20151 $0-21140 C$.

86. Miners JO, Yang X, Knights KM, Zhang L. The role of the kidney in drug elimination: transport, metabolism, and the impact of kidney disease on drug clearance. Clin Pharmacol Ther. 2017;102(3):436-49. https://doi.org/10.1002/cpt.757.

87. Ashraf M, Shahzad N, Irshad M, Hussain SQ, Ahmed P. Pediatric acute kidney injury: a syndrome under paradigm shift. Indian J Crit Care Med. 2014;18(8):518-26. https://doi. org/10.4103/0972-5229.138156.

88. Poston JT, Koyner JL. Sepsis associated acute kidney injury. BMJ. 2019;364:k4891. https://doi.org/10.1136/bmj.k4891.

89. Zappitelli M, Washburn KK, Arikan AA, Loftis L, Ma Q, Devarajan $\mathrm{P}$, et al. Urine neutrophil gelatinase-associated lipocalin is an early marker of acute kidney injury in critically ill children: a prospective cohort study. Crit Care. 2007;11(4):R84. https://doi.org/10.1186/cc6089.

90. Chen N, Aleksa K, Woodland C, Rieder M, Koren G. Ontogeny of drug elimination by the human kidney. Pediatr Nephrol. 2006;21(2):160-8. https://doi.org/10.1007/s00467-005-2105-4.

91. Hayton WL. Maturation and growth of renal function: dosing renally cleared drugs in children. AAPS Pharm Sci. 2000;2(1):E3. https://doi.org/10.1208/ps020103.

92. Mouton JW, Muller AE, Canton R, Giske CG, Kahlmeter G, Turnidge J. MIC-based dose adjustment: facts and fables. J Antimicrob Chemother. 2018;73(3):564-8. https://doi.org/10.1093/ $\mathrm{jac} / \mathrm{dkx} 427$.

93. Mouton JW. Soup with or without meatballs: impact of nutritional factors on the MIC, kill-rates and growth-rates. Eur J Pharm Sci. 2018;125:23-7. https://doi.org/10.1016/j.ejps.2018.09.008.

94. Woksepp H, Hallgren A, Borgstrom S, Kullberg F, Wimmerstedt A, Oscarsson A, et al. High target attainment for beta-lactam antibiotics in intensive care unit patients when actual minimum inhibitory concentrations are applied. Eur J Clin Microbiol Infect Dis. 2016. https://doi.org/10.1007/s10096-016-2832-4.

95. Kumaraswamy M, Lin L, Olson J, Sun CF, Nonejuie P, Corriden $\mathrm{R}$, et al. Standard susceptibility testing overlooks potent azithromycin activity and cationic peptide synergy against
MDR Stenotrophomonas maltophilia. J Antimicrob Chemother. 2016;71(5):1264-9. https://doi.org/10.1093/jac/dkv487.

96. Nielsen EI, Cars O, Friberg LE. Pharmacokinetic/pharmacodynamic (PK/PD) indices of antibiotics predicted by a semimechanistic PKPD model: a step toward model-based dose optimization. Antimicrob Agents Chemother. 2011;55(10):4619-30. https ://doi.org/10.1128/AAC.00182-11.

97. Guilhaumou R, Benaboud S, Bennis Y, Dahyot-Fizelier C, Dailly E, Gandia P, et al. Optimization of the treatment with beta-lactam antibiotics in critically ill patients-guidelines from the French Society of Pharmacology and Therapeutics (Societe Francaise de Pharmacologie et Therapeutique-SFPT) and the French Society of Anaesthesia and Intensive Care Medicine (Societe Francaise d'Anesthesie et Reanimation-SFAR). Crit Care. 2019;23(1):104. https://doi.org/10.1186/s13054-019-2378-9.

98. Abdul-Aziz MH, Sulaiman H, Mat-Nor MB, Rai V, Wong KK, Hasan MS, et al. Beta-Lactam Infusion in Severe Sepsis (BLISS): a prospective, two-centre, open-labelled randomised controlled trial of continuous versus intermittent beta-lactam infusion in critically ill patients with severe sepsis. Intensive Care Med. 2016;42(10):1535-45. https://doi.org/10.1007/s0013 4-015-4188-0.

99. Falagas ME, Tansarli GS, Ikawa K, Vardakas KZ. Clinical outcomes with extended or continuous versus short-term intravenous infusion of carbapenems and piperacillin/tazobactam: a systematic review and meta-analysis. Clin Infect Dis. 2013;56(2):27282. https://doi.org/10.1093/cid/cis857.

100. Hao JJ, Chen H, Zhou JX. Continuous versus intermittent infusion of vancomycin in adult patients: a systematic review and meta-analysis. Int J Antimicrob Agents. 2016;47(1):28-35. https ://doi.org/10.1016/j.ijantimicag.2015.10.019.

101. Roberts JA, Abdul-Aziz MH, Davis JS, Dulhunty JM, Cotta MO, Myburgh J, et al. Continuous versus intermittent betalactam infusion in severe sepsis. A meta-analysis of individual patient data from randomized trials. Am J Respir Crit Care Med. 2016;194(6):681-91. https://doi.org/10.1164/rccm.20160 1-0024oc.

102. Roberts JA, Webb S, Paterson D, Ho KM, Lipman J. A systematic review on clinical benefits of continuous administration of beta-lactam antibiotics. Crit Care Med. 2009;37(6):2071-8. https ://doi.org/10.1097/CCM.0b013e3181a0054d.

103. Teo J, Liew Y, Lee W, Kwa AL. Prolonged infusion versus intermittent boluses of beta-lactam antibiotics for treatment of acute infections: a meta-analysis. Int J Antimicrob Agents. 2014;43(5):403-11. https://doi.org/10.1016/j.ijantimica g.2014.01.027. 